\title{
Radiative characteristics of aerosol during extreme fire event over Siberia in summer 2012
}

\author{
Tatiana B. Zhuravleva ${ }^{1}$, Dmitriy M. Kabanov ${ }^{1}$, Ilmir M. Nasrtdinov ${ }^{1}$, Tatiana V. Russkova ${ }^{1}$, Sergey M. Sakerin ${ }^{1}$, \\ Alexander Smirnov ${ }^{2,3}$, and Brent N. Holben ${ }^{3}$ \\ ${ }^{1}$ Division of Radiative Components of Climate and Optical Diagnostics of the Environment, \\ V. E. Zuev Institute of Atmospheric Optics SB RAS, Tomsk, Russia \\ ${ }^{2}$ Science Systems and Applications, Inc., Lanham, MD, USA \\ ${ }^{3}$ NASA Goddard Space Flight Center, Greenbelt, MD, USA
}

Correspondence to: Tatiana B. Zhuravleva (ztb@iao.ru)

Received: 19 July 2016 - Published in Atmos. Meas. Tech. Discuss.: 15 August 2016

Revised: 21 November 2016 - Accepted: 28 November 2016 - Published: 13 January 2017

\begin{abstract}
Microphysical and optical properties of aerosol were studied during a mega-fire event in summer 2012 over Siberia using ground-based measurements of spectral solar radiation at the AERONET site in Tomsk and satellite observations. The data were analysed using multi-year (20032013) measurements of aerosol characteristics under background conditions and for less intense fires, differing in burning biomass type, stage of fire, remoteness from observation site, etc. ("ordinary" smoke). In June-August 2012, the average aerosol optical depth (AOD, $500 \mathrm{~nm}$ ) had been $0.95 \pm 0.86$, about a factor of 6 larger than background values $(0.16 \pm 0.08)$, and a factor of 2.5 larger than in ordinary smoke. The AOD values were extremely high on 2428 July and reached 3-5. A comparison with satellite observations showed that ground-based measurements in the region of Tomsk not only reflect the local AOD features, but are also characteristic for the territory of Western Siberia as a whole. Single scattering albedo (SSA, $440 \mathrm{~nm}$ ) in this period ranged from 0.91 to 0.99 with an average of $\sim 0.96$ in the entire wavelength range of 440-1020 nm. The increase in absorptance of aerosol particles $(\operatorname{SSA}(440 \mathrm{~nm})=0.92)$ and decrease in SSA with wavelength observed in ordinary smoke agree with the data from multi-year observations in analogous situations in the boreal zone of USA and Canada. Volume aerosol size distribution in extreme and ordinary smoke had a bimodal character with significant prevalence of finemode particles, but in summer 2012 the mean median radius and the width of the fine-mode distribution somewhat increased. In contrast to data from multi-year observations,
\end{abstract}

in summer 2012 an increase in the volume concentration and median radius of the coarse mode was observed with growing AOD.

The calculations of the average radiative effects of smoke and background aerosol are presented. Compared to background conditions and ordinary smoke, under the extreme smoke conditions the cooling effect of aerosol considerably intensifies: direct radiative effects (DRE) at the bottom (BOA) and at the top of the atmosphere (TOA) are $-13,-35$, and $-60 \mathrm{~W} \mathrm{~m}^{-2}$ and $-5,-14$, and $-35 \mathrm{~W} \mathrm{~m}^{-2}$ respectively. The maximal values of DRE were observed on 27 July $(\operatorname{AOD}(500 \mathrm{~nm})=3.5)$, when $\mathrm{DRE}(\mathrm{BOA})$ reached $-150 \mathrm{~W} \mathrm{~m}^{-2}$, while DRE(TOA) and DRE of the atmosphere were $-75 \mathrm{~W} \mathrm{~m}^{-2}$. During the fire event in summer 2012 the direct radiative effect efficiency varied in range: at the BOA it was $-80--40 \mathrm{~W} \mathrm{~m}^{-2}$, at the TOA it was $-50--20 \mathrm{~W} \mathrm{~m}^{-2}$ and in the atmosphere it was $-35--20 \mathrm{~W} \mathrm{~m}^{-2}$.

\section{Introduction}

Massive forest and peat fires are the greatest source of aerosol-gas emissions in the boreal zone of northern Eurasia. In addition to the anthropogenic factor, biomass ignition is favoured by dangerous consequences of global climate warming, manifested in the form of strong temperature, circulation, and hydrologic anomalies (Groisman et al., 2007). In view of enormous stretches of the boreal zone, fires occur in some or another region of this vast territory almost every 
year and strongly influence the radiation budget, air quality, human health, biological diversity, glaciology, etc. To understand the effects of biomass burning on the atmosphere, the physical, chemical, and optical properties of smoke particles need to be studied and parameterized with reliable uncertainties.

Since the 1990s, a large amount of information on characteristics of carbonaceous particles based on in situ measurements and remote sensing using ground-, aircraft-, and satellite-based instruments has been accumulated in hundreds of manuscripts. However, even with the availability of such a volume of data, the determination of key parameters for estimating atmospheric effects of biomass burning is not straightforward, primarily because the smoke properties strongly depend on the set of a variety of reasons, the most important of which are the type of biomass, the stage of fire, meteorological conditions at the fire site and in the territory of the dispersal of smoke plumes, age of smoke, etc. (see e.g. the reviews Dubovik et al., 2002; Reid et al., 2005a, b; Bond and Bergstrom, 2006; Moosmüller et al., 2009; Giles et al., 2012; Sayer et al., 2014; Nikonovas et al., 2015 and bibliography therein). Another problem is that specific features of individual fires may strongly differ from the ensemble smoke hazes that are a result of some averaging procedures of characteristics of numerous fires. This aspect is crucial for studying the radiation effects of aerosol because, in the framework of regional and global climate models, the most important issue is the development of model representations concerning the aged smoke that dominates regional hazes and affects climate.

A stable anticyclone had formed in summer 2012 in Siberia under the conditions of a small-gradient highpressure baric field (Polyakov et al., 2014), with the consequences being that forest and peat fires burned in a few regions of Siberia and encompassed the territory from 1 to 10 million hectares, by different estimates. Optical and microphysical properties of near-ground aerosol and specific features of their vertical structure according to data from in situ measurements, as well as spatio-temporal evolution of aerosol optical depth and active fires according to results of satellite monitoring, are presented in (Gorchakov et al., 2014; Kozlov et al., 2014; Sklyadneva et al., 2015; Vinogradova et al., 2015; Panchenko et al., 2016). In our work, we discuss the columnar optical and microphysical aerosol characteristics, retrieved on the basis of ground-based photometric observations in Tomsk during the extreme fire event in 2012. The second aim is to compare these results with data from multi-year photometric measurements and satellite observations over Western Siberia under different atmospheric conditions.

\section{Instrumentation, sites, and methods}

\subsection{Ground-based measurements}

The measurements, presented in this paper, were made with a CIMEL Electronique CE 318 sun-sky radiometer, which is a part of AErosol RObotic NETwork (AERONET, Holben et al., 1998). These measurements were performed in eastern suburb of Tomsk (Tomsk: $56.48^{\circ} \mathrm{N} ; 85.05^{\circ} \mathrm{E}$ ) in the period of 2003-2010; and since 2011, CE 318 operated at the Fonovaya observatory located $60 \mathrm{~km}$ away from the city (Tomsk22: $56.42^{\circ} \mathrm{N} ; 84.07^{\circ} \mathrm{E}$ ).

Direct sun measurements are made in the spectral channels centred at 340,380, 440,500,675, 870, 940, and $1020 \mathrm{~nm}$ (bandwidth: $10 \mathrm{~nm}$ at full width at half maximum). These solar extinction data are then used to compute aerosol optical depth (AOD, $\tau_{\lambda}$ ) at each wavelength $\lambda$ except $940 \mathrm{~nm}$, which is used to retrieve total columnar content of water vapour $(W)$. The spectral aerosol optical depth data have been screened for clouds following the methodology of Smirnov et al. (2000). In addition to direct sun measurements, radiation measurements in solar almucantar are made in four channels of CE 318: 440, 675, 870, and $1020 \mathrm{~nm}$. These data and the inverse automated algorithm by Dubovik and King (2000) (version 1) with enhancements (version 2, Holben et al., 2006) were used to retrieve other aerosol characteristics: volume particle size distribution function $\mathrm{d} V / \mathrm{d} \ln r\left(\mu \mathrm{m}^{3} \mu \mathrm{m}^{-2}\right)$, scattering phase function, asymmetry factor $g_{\lambda}$, complex refractive index $\left(n_{\lambda}-\kappa_{\lambda} \times i\right)$, and single scattering albedo $\omega_{\lambda}$.

Dubovik et al. (2000) presented uncertainties of retrieval estimates for volume size distribution, refractive index, and single scattering albedo (SSA). For Level 2 data at moderate aerosol loading ( $\tau_{440} \sim 0.4$ ) uncertainties for such retrievals are $10-35 \%$ for the binned size distribution in the intermediate particle size range $(0.1 \leq r \leq 7 \mu \mathrm{m}), 0.04$ and $30-50 \%$ for the real and imaginary parts of the refractive index, and 0.03 for single scattering albedo. For typical biomass burning models (Dubovik et al., 2002) these uncertainties were propagated onto the other size distribution parameters (Sayer et al., 2014): the volume mean radius $r_{\mathrm{v}}$ and standard deviation $\sigma$ of fine (f) and coarse (c) modes are retrieved with errors $0.01 \mu \mathrm{m}$ for $r_{\mathrm{v}}^{\mathrm{f}}, 0.2 \mu \mathrm{m}$ for $r_{\mathrm{v}}^{\mathrm{c}}$, and 0.06 for $\sigma^{\mathrm{f}}$ and $\sigma^{\mathrm{c}}$. This led to uncertainties of $\sim 0.015-0.04$ in the asymmetry factor (AF) of fine-mode aerosol (larger uncertainties at longer wavelengths) and $\sim 0.01$ in the coarse-mode aerosol (smaller uncertainties at longer wavelengths).

An original approach, relying upon ground-based spectral measurements of AOD and radiance phase functions, was also used in addition to the algorithm by Dubovik and King (2000) to solve the inverse problem. The first version of the algorithm, namely, Sun-Sky Measurements for Aerosol ReTrieval (SSMART 1.1 software package), was implemented under the assumption of (a) the sphericity of aerosol particles and (b) the independence of the complex refractive index on the wavelength and particle size (Bedareva 
et al., 2013a). An improved version of the algorithm (SSMART 1.2), in which the inverse light scattering problem was solved using the model of a mixture of randomly oriented polydisperse spheroids, was suggested by Bedareva et al. (2014). In both versions, the aerosol optical characteristics are derived in two ways: directly from the spectral sunsky radiometer measurements (Way 1) and through the calculation based on the retrieved particle size distribution and complex refractive index (Way 2). On the basis of closed numerical experiments, the accuracy of aerosol retrievals was investigated in error-free conditions and in the presence of measurement errors. The SSMART algorithm was tested on conditions of moderate and increased aerosol turbidity of the atmosphere at Tomsk and Dakar $\left(14^{\circ} \mathrm{N}, 16^{\circ} \mathrm{W}\right)$ AERONET sites. It was found that the SSMART and AERONET codes give consistent estimates of aerosol properties within their retrieval uncertainties (Bedareva et al., 2013a, b, 2014).

Measured aerosol optical depth and computed retrieval products were used to derive additional aerosol properties. Spectral dependence of AOD is traditionally described by the empirical Ångström formula:

$\tau_{\lambda}=\beta \lambda^{-\alpha}$.

The absorption AOD (AAOD) is calculated for each wavelength using the following equation (Giles et al., 2012):

$\tau_{\mathrm{abs}, \lambda}=\tau_{\lambda} \times\left[1-\omega_{\lambda}\right]$.

Similarly to Eq. (1), it can be represented as

$\tau_{\mathrm{abs}, \lambda}=\beta_{\mathrm{abs}} \lambda^{-\alpha_{\mathrm{abs}}}$.

Having analysed the radiative characteristics of smoke aerosol in summer 2012 (hereinafter referred to as extreme smoke), we additionally employed data from multi-year AOD observations at Tomsk and Tomsk-22 sites, obtained from April to October in 2003-2011 and in 2013. Using the method by Kabanov and Sakerin (2006), the total data set was divided into two subsets: (1) background (usual) conditions (998 days) and (2) ordinary smoke conditions (81 days). By "ordinary" smoke we mean smoke conditions from yearly observed Siberian biomass burning of different types (forest and peat fires, springtime vegetation burning, smoke from remote sources), which are shorter and less severe than the extreme smoke conditions. Simultaneous measurements at these sites revealed no statistically significant AOD differences in the warm period of the year (Sakerin et al., 2010); therefore, the data merging obtained at the neighbouring sites (Tomsk and Tomsk-22) can be regarded as correct.

The smaller data volume underwent a comparative analysis of aerosol optical and microphysical characteristics obtained from the inverse procedure. The number of retrievals from the total set of characteristics, including refractive index, single scattering albedo, volume size distribution function, and scattering phase function (Level 2, $\tau_{440}>0.4$ ), was 65 in the period of the extreme smoke (15 June10 August 2012) and 140 under the conditions of ordinary smoke (April-October 2003-2011, 2013). Out of 140 ordinary smoke conditions, the maximal number of almucantar retrievals was 39 (2004), 23 (2006), and 22 (2013). In these data, results obtained in May 2004 deserve special attention. Dry and warm weather, predominating in the regions of Novosibirsk and Tomsk (with air temperatures exceeding $30{ }^{\circ} \mathrm{C}$ on separate days), led to numerous forest fires, provoked by the burning of the previous year's vegetation and bonfires left unextinguished by fishers and hunters. The number of retrieved aerosol characteristics varied from 1 (2005) to 15 (2008) for remaining period of multi-year observations.

\subsection{Satellite data}

AOD observations at $550 \mathrm{~nm}$ (collection 6, http://giovanni. sci.gsfc.nasa.gov/giovanni/) from MODIS (Moderate Resolution Imaging Spectroradiometer) instruments were used. This MODIS product (TERRA and AQUA platforms, Level 3 data, i.e. daily averaged within the grid cells $1^{\circ} \times 1^{\circ}$ ) was obtained using the algorithm from Levy et al. (2013).

\section{General characteristics of the large-scale smoke pollution in the summer of 2012}

In this section, we present the general characteristics of smoke conditions in 2012 in Tomsk.

\subsection{Weather-climate features}

In summer 2012, a stable anticyclone had formed over the territory of Siberia under the conditions of a smallgradient high-pressure baric field (Polyakov et al., 2014). The consequences were substantial changes in climatically significant characteristics and, primarily, an appreciable increase in air temperature, and a decrease in precipitation. Data from observations at Tomsk meteorological station (WMO_ID = 29430 , http://rp5.ru) indicate that monthly mean temperature in July was maximal over the last decade, while the amount of precipitation was close to a minimum (Fig. 1). On the whole, positive anomalies of temperature reached $1.3-7.2^{\circ} \mathrm{C}$ in June-July in Tomsk $\left(\sim 56-61^{\circ} \mathrm{N} ; 75\right.$ $88^{\circ} \mathrm{E}$ ), and the amount of precipitation was $20-30 \%$ of climatic norm. A Selyaninov hydrothermal wetting coefficient was also used as a characteristic of a wetting (drought) regime (see e.g. Polyakov et al., 2014); it is defined as the ratio of total precipitation for a period no shorter than 1 month to the sum of temperatures for the same period, decreased by a factor of 10. Polyakov et al. (2014) showed that, over the last 70 years, the atmospheric droughts in Tomsk were longer than 1 month over 9 summers (the hydrothermal wetting coefficient varied from 0.6 to 1.4), with the summer of 2012 being the driest. 


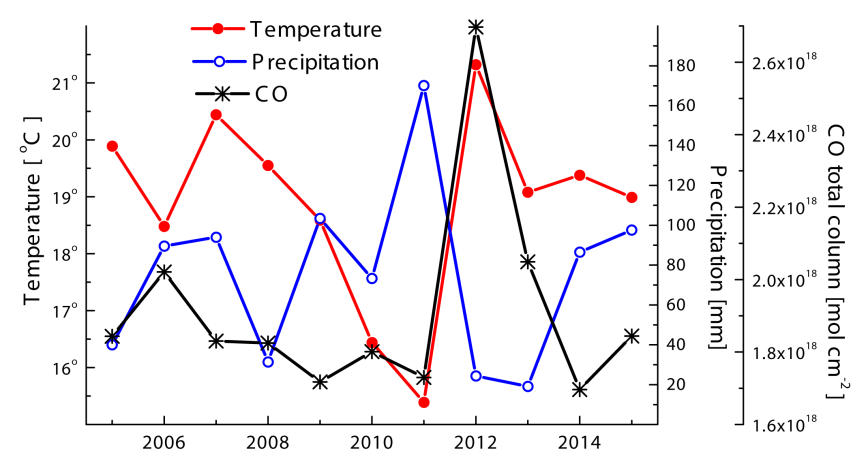

Figure 1. Interannual variations in average July temperatures and the amount of precipitation according to data from the Tomsk meteorological station, as well as interannual variations in total carbon monoxide content according to satellite observations over the territory of Tomsk (http://giovanni.sci.gsfc.nasa.gov/).

These conditions led to extensive forest fires in Western and Eastern Siberia (Fig. 2), accompanied by considerable pollution of the atmosphere by combustion products (smoke particles, carbon and nitrogen oxides, etc.). Groundbased observations in Tomsk indicate that, in the period of maximal smoke pollution on 25-28 July 2012, the aerosol number concentration had been $3000-8500 \mathrm{~cm}^{-3}$ (particle diameter of $0.25-30 \mu \mathrm{m}$ ), exceeding the background values by about a factor of 20 , while carbon monoxide concentrations reached $7.7 \mathrm{ppm}$ (Sklyadneva et al., 2015). Results of satellite (AIRS/TERRA) monitoring indicate that the Julyaverage total $\mathrm{CO}$ content over the territory of Tomsk region in 2012 increased by approximately $40 \%$ (Fig. 1) compared to 2005-2015 (except 2012).

An anticyclone over Western Siberia persisted for almost 2 months (second half of June to the first ten days of August), similar to anomalous situations observed over the European territory of Russia in 1972 and 2010 (Shakina and Ivanova, 2010). After 8-10 August, the blocking cyclone started to break, heat rapidly weakened, and air temperature returned to within the climatic norm at all meteorological stations of Tomsk region (Polyakov et al., 2014).

\subsection{Aerosol radiation characteristics}

\subsubsection{Ground-based observations}

Figure $3 \mathrm{a}, \mathrm{b}, \mathrm{c}$ shows the time variations in daily average values of AOD, single scattering albedo $\omega_{440}$, and asymmetry factor $g_{440}$ in the summer period of 2012.

The AOD data indicate that there are two waves of high atmospheric smoke turbidities, from 17 June to 5 July and from 19 July to 6 August. Maximal AOD values $(500 \mathrm{~nm})$ reaching 3-5 were observed on 3-6 July and 25-29 July.

The single scattering albedos did not go out of the interval $0.93 \leq \omega_{440} \leq 0.99$ in almost all cases. The asymmetry factor $g_{440}$ varied from 0.66 to 0.74 , i.e. in the same range

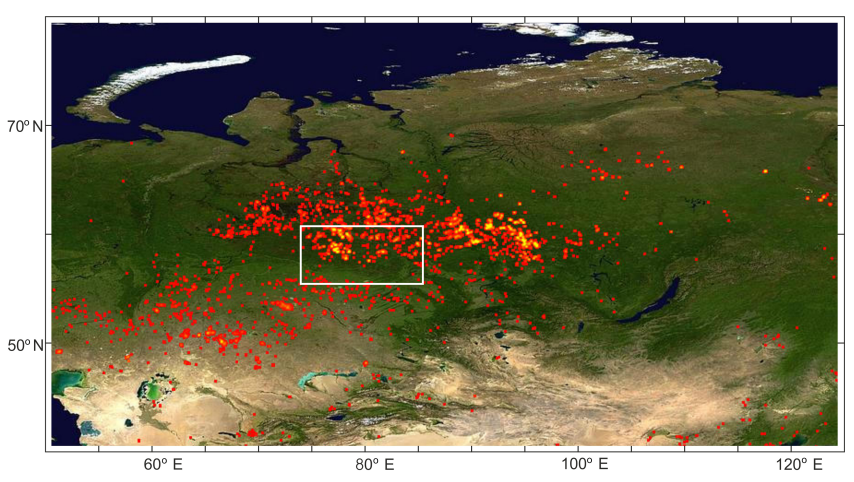

Figure 2. The map of forest fires over Siberia in the period from 19 to 28 July 2012 (http://lance-modis.eosdis.nasa.gov/cgi-bin/ imagery/firemaps.cgi). The Tomsk region $\left(56-61^{\circ} \mathrm{N} ; 75-88^{\circ} \mathrm{E}\right)$ is highlighted by a box.

as multi-year average values in the territory of Siberia (Sakerin, 2012; Sakerin et al., 2009, 2014). From the results presented here it also follows that, on those days when SSA and AF were retrieved by two methods, the SSMART and AERONET codes gave consistent estimates of aerosol properties within their retrieval uncertainties.

The arrival of smoke plumes was also accompanied by a substantial increase in the mass concentrations of black carbon $\left(M_{\mathrm{BC}}\right)$ and aerosol $\left(M_{\mathrm{a}}\right)$ in the near-ground atmospheric layer. Kozlov et al. (2014) showed that the average values of these characteristics at the Fonovaya observatory in the period from 17 June to 4 August varied in the ranges $M_{\mathrm{BC}}=1.9-10.3 \mu \mathrm{g} \mathrm{m}^{-3}$ and $M_{\mathrm{a}}=103-425 \mu \mathrm{g} \mathrm{m}^{-3}$ given the background levels of $\sim 0.45$ and $\sim 20 \mu \mathrm{g} \mathrm{m}^{-3}$ respectively for 10-31 August. Similar to AOD, the maximal concentrations of $M_{\mathrm{BC}}$ and $M_{\mathrm{a}}$ were observed in the period of 25-29 July.

The examples of daily average aerosol volume size distribution $\mathrm{d} V / \mathrm{d} \ln r$ for moderate to high AOD values are presented in Fig. 3d. A noticeable salient feature of the $\mathrm{d} V / \mathrm{d} \ln r$ distribution is the increase in the modal radius and in the width of the fine aerosol fraction during extreme turbidity on 28 July compared to periods on 27 June and 14 July, when AOD was much lower.

A consequence of anomalously high atmospheric turbidities was substantial changes in solar radiation reaching the earth's surface. Figure 4 illustrates the daytime behaviour of direct and diffuse radiative fluxes, measured with an MS-53 pyrheliometer and MS-802 pyranometer $(0.305-2.8 \mu \mathrm{m})$ under usual (background) conditions on 24 July $2011\left(\tau_{500}=\right.$ $0.07)$ and in the highly turbid atmosphere on 28 July 2012 $\left(\tau_{500}=2.14\right)$. Under the influence of smoke plume, there was a 2- to 4-fold decrease in direct radiation, which was partially compensated for by an approximately equal increase in diffuse radiation. The diffuse radiation was considerably larger (a factor of $\sim 1.8$ ) than the direct radiation throughout the day (28 July 2012). 

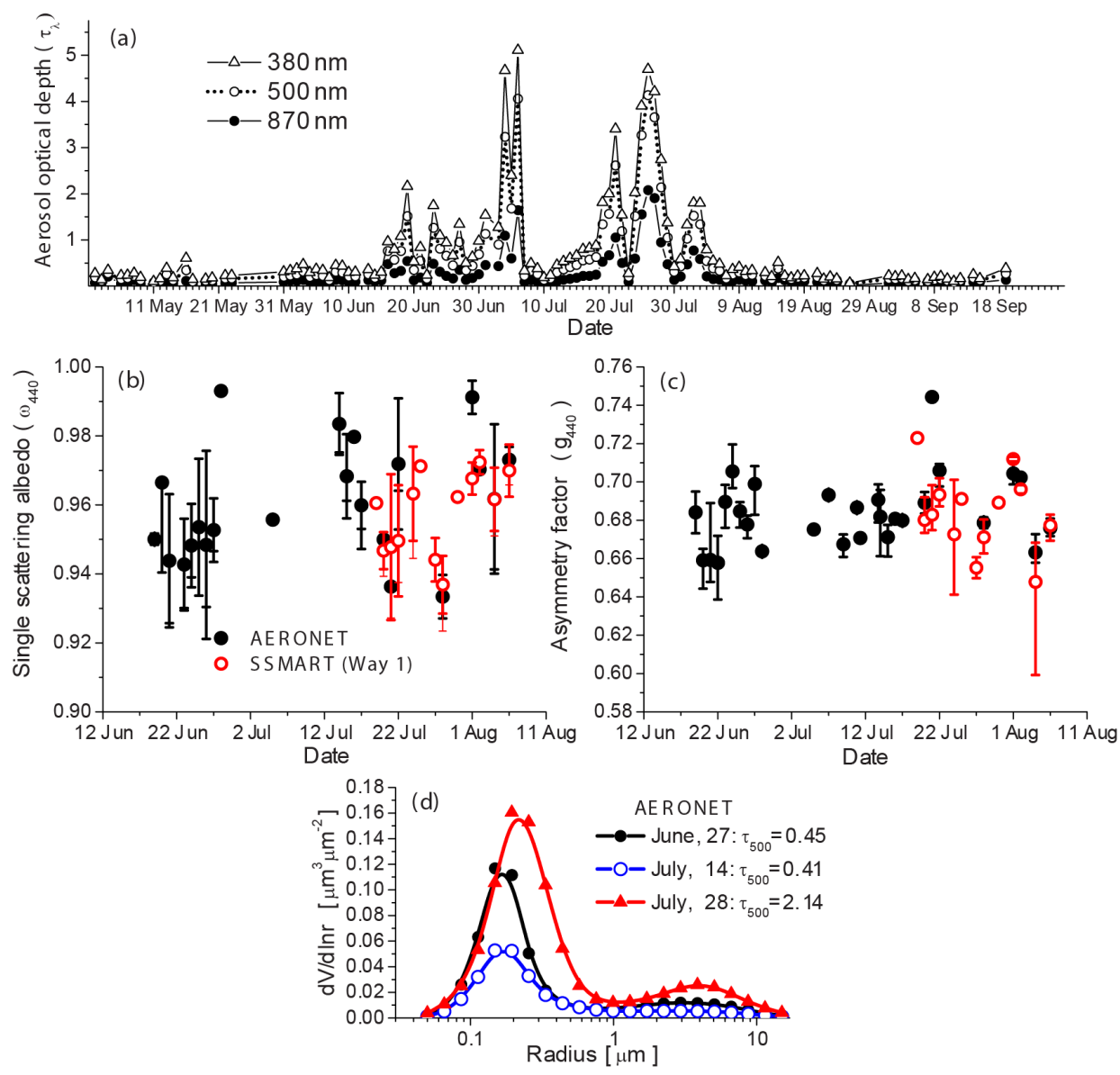

Figure 3. (a) Daily average AOD, (b) single scattering albedo and (c) asymmetry factor time series, and (d) examples of particle size distribution in Tomsk-22 during the summer period of 2012.
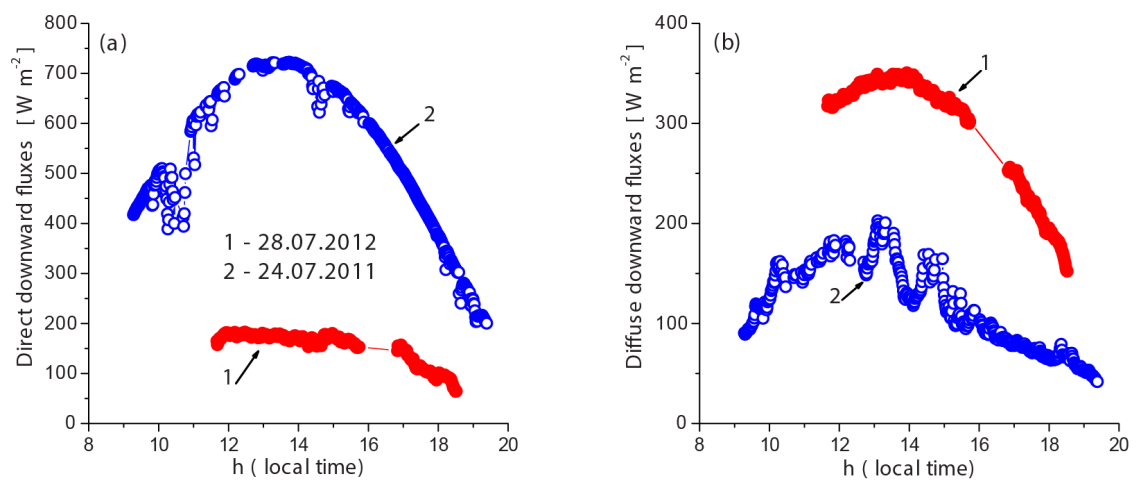

Figure 4. Daytime behaviour of (a) direct and (b) diffuse fluxes of solar radiation under the usual conditions (24 July 2011) and during extreme smoke conditions (28 July 2012) in the region of the Fonovaya observatory.

\subsubsection{Satellite observations}

The spatial distributions of AOD at $550 \mathrm{~nm}$ over Western Siberia and partially over Eastern Siberia $\left(60-100^{\circ} \mathrm{N}, 52-\right.$ $70^{\circ} \mathrm{E}$ ), averaged over the period of 15 June-10 August 2012, are presented in Fig. 5. These data show that the territory of the Tomsk region in this period was subjected to an intensive influence of large-scale smoke pollution and characterized by high values of AOD. 


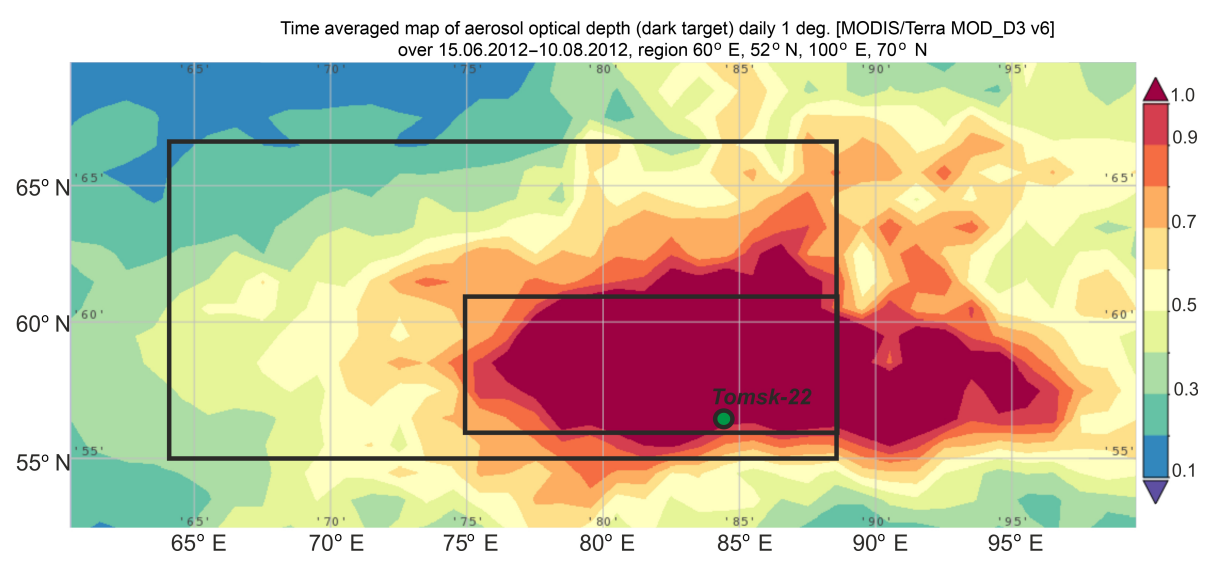

Figure 5. Spatial distributions of AOD (MODIS collection 6) over Western and Eastern Siberia during 15 June-10 August 2012. The central part of Western Siberia $\left(55-62^{\circ} \mathrm{N} ; 64-88^{\circ} \mathrm{E}\right)$ and the Tomsk region $\left(56-61^{\circ} \mathrm{N} ; 75-88^{\circ} \mathrm{E}\right)$ are highlighted by boxes.
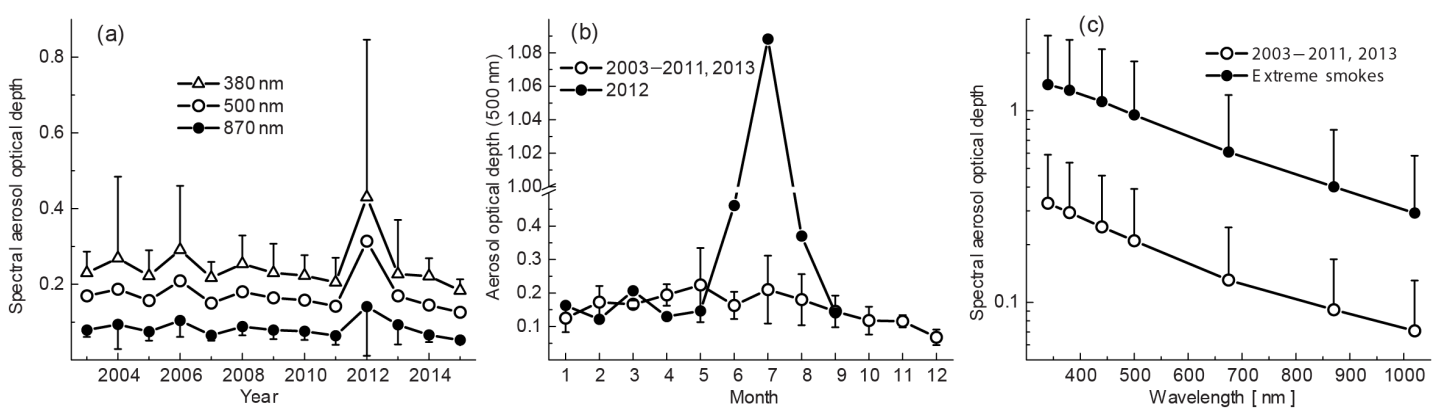

Figure 6. (a) Multi-year averages and standard deviations of spectral aerosol optical depth, (b) monthly averages of $\tau_{500}$ in 2012 compared with the multi-year averages for the period of 2003-2011, 2013, and (c) average spectral AOD dependences in the period of 2012 extreme smoke compared to multi-year data in July (Tomsk, 2003-2011, 2013, combined data set of smoke and background conditions). One-sided error bars are used in order not to overburden the figures.

\section{Discussion of results}

\subsection{Temporal and spectral variability of aerosol optical depth}

\subsubsection{Ground-based data}

An analysis of multi-year AOD variations in a few regions of Russia according to data from photometric observations showed that, after eruption products of Pinatubo volcano had sunk out of the stratosphere, the interannual AOD variations were small and no statistically significant trend was observed in the past two decades (Sakerin, 2012; Sakerin et al., 2009; Sakerin and Kabanov, 2015). For instance, the annually average AOD values $(500 \mathrm{~nm})$ in Tomsk during the period of 2003-2015 (except in 2012) varied from 0.13 to 0.21 (Fig. 6a).

Under the influence of massive forest fires in Siberia during summer 2012, the annual AOD value exceeded the multiyear norm by almost a factor of 2 and became the highest over the entire period of photometric observations in Tomsk (since 1992) (Sakerin and Kabanov, 2015). Average summer- time AOD values changed even more: in particular, the average value of $\tau_{500}$ in July increased by a factor of $4.5 \mathrm{com}$ pared to multi-year data (Fig. 6b). Even if we omit anomalously high turbidities $\left(\tau_{500}>1\right)$, which may be partly due to clouds that are invisible through haze, the average AOD values in summer months of 2012 are outside the values defined when taking into account standard deviations (SDs).

More detailed characteristics of atmospheric AOD for three wavelengths in UV, visible, and near-infrared ranges during the extreme smoke in comparison with the multi-year average data for July are presented in Table 1. Also given are the average characteristics for various conditions of ordinary smoke, which are observed every year in Siberia in the warm period. The comparison showed (see also Fig. 6c) that AOD exceeds the background values by a factor of 5.56 in the entire spectral range during an extreme fire event in 2012. In absolute value, AOD increased more significantly in the shortwave part of spectrum, i.e. due to fine aerosol frac-

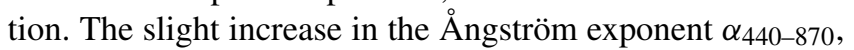
which depends mainly on the interrelation between contributions of fine and coarse aerosols to AOD, also indicates that small particles predominate in smoke aerosol. Despite 
Table 1. Average $( \pm$ SD) characteristics of AOD and water vapour content of the atmosphere during the period of extreme smoke in 2012 compared to multi-year data for July and ordinary smoke (April-October 2003-2011 and 2013).

\begin{tabular}{|c|c|c|c|c|}
\hline \multirow[t]{2}{*}{ Characteristics } & \multicolumn{2}{|c|}{ July, multi-year } & \multirow{2}{*}{$\begin{array}{r}\text { Extreme smoke } \\
\text { (17 Jun-6 Aug 2012) }\end{array}$} & \multirow[t]{2}{*}{ Ordinary smoke } \\
\hline & $\begin{array}{r}\text { Background } \\
\text { conditions }\end{array}$ & $\begin{array}{l}\text { Total data set } \\
\text { (with smoke) }\end{array}$ & & \\
\hline$\tau_{340}$ & $0.25 \pm 0.11$ & $0.33 \pm 0.26$ & $1.37 \pm 1.10$ & $0.58 \pm 0.28$ \\
\hline$\tau_{500}$ & $0.16 \pm 0.08$ & $0.21 \pm 0.18$ & $0.95 \pm 0.86$ & $0.36 \pm 0.18$ \\
\hline$\tau_{870}$ & $0.07 \pm 0.04$ & $0.09 \pm 0.08$ & $0.40 \pm 0.40$ & $0.15 \pm 0.09$ \\
\hline$\frac{\alpha_{440-870}}{\alpha_{340-500}}$ & $\frac{1.48 \pm 0.29}{1.48 \pm 0.22}$ & $\frac{1.49 \pm 0.28}{1.44 \pm 0.22}$ & $\frac{1.58 \pm 0.21}{1.24 \pm 0.34}$ & $\frac{1.59 \pm 0.22}{1.43 \pm 0.25}$ \\
\hline$\frac{\beta_{440-870}}{\beta_{340-500}}$ & $\frac{0.058 \pm 0.037}{0.049 \pm 0.04}$ & $\frac{0.074 \pm 0.064}{0.072 \pm 0.092}$ & $\frac{0.33 \pm 0.35}{0.479 \pm 0.611}$ & $\frac{0.12 \pm 0.071}{0.12 \pm 0.081}$ \\
\hline$W, \mathrm{~g} \mathrm{~cm}^{-2}$ & $2.09 \pm 0.56$ & $2.16 \pm 0.57$ & $2.19 \pm 0.58$ & $1.93 \pm 0.79$ \\
\hline
\end{tabular}

the temperature, aerosol, and other anomalies, the total water vapour content of the atmosphere in the period of strong fires differed little from the multi-year norm.

Average AOD characteristics in ordinary smoke incorporate data for fires of different types and distances from the region of measurements and, as such, occupy an intermediate position between background conditions and extreme smoke. Independent of their intensity, a common feature of all smoke is an identical exponent $\alpha$, which characterizes a higher content of fine aerosol.

It is noteworthy that the multi-year average values of $\alpha_{440-870}$ and AOD in the near-infrared range, calculated for background conditions and total data set, differ little (see columns 2 and 3 in Table 1), primarily because of relatively small number (about $8 \%$ ) of smoke conditions in the total data set.

Under the assumption that aerosol size distributions are bimodal, O'Neil et al. (2001, 2003) have developed a spectral deconvolution algorithm (SDA) to infer the component fine- and coarse-mode optical depths from the spectral dependence of AOD. In June-August 2012, the coarse-mode $\tau_{500}^{\mathrm{c}}$ is less than fine-mode $\tau_{500}^{\mathrm{f}}$ and is typically low (only 3 days show that $\tau_{500}^{\mathrm{c}} \sim 0.2$ ), whereas $\tau_{500}^{\mathrm{f}}$ is high and exhibits very large day-to-day variability (Fig. 7a). The parameter $\eta_{500}$, which characterizes the contribution of fine fraction to AOD at $500 \mathrm{~nm}$, exceeded 0.7 and approached 0.9 at $\tau_{500} \geq 0.6$ (Fig. $7 b$ ). These results are consistent with earlier published data, according to which the content of fine aerosol fraction predominately increases during vegetation burning in the absence of any other significant sources (Reid et al., 2005b; Eck et al., 2009; Giles et al., 2012).

\subsubsection{Analysis of satellite observations}

The analysis of spatio-temporal AOD variations was confined to the consideration of the central part of Western Siberia. A salient feature of this territory is a uniform landscape (without mountainous terrain) and the absence of large sources of anthropogenic pollution. Under usual conditions, the AOD values, retrieved from satellite observations, are characterized by small (background) values and by quite a uniform spatial distribution (Zhuravleva et al., 2009; Sakerin, 2012).

Since the formation and evolution of smoke plumes are strongly affected by large-scale atmospheric dynamics, spatial distributions of AOD may substantially change from one day to another. The main specific features of variations can be identified through the analysis of AOD fields, averaged for a few 5-day periods, selected by taking into account the ground-based observations (Fig. 3a). On 6-10 June there were background conditions (before beginning of forest fires), on 1-5 and 24-28 July there were maximal smoke turbidities, and on 10-14 July there were relatively low AOD values observed between two turbidity maxima. Hereinafter, for calculations of the AOD values averaged over the selected time interval ( 5 days), we used the daily satellite product.

Spatial AOD distributions, presented in Fig. 8, show that the Tomsk-22 observation site was either at the centre (Fig. 8b) or on the periphery of smoke plumes (Fig. 8a) in different periods of time. The periods of small turbidities of the atmosphere (on 6-10 June and 10-14 July) were characterized by quite a uniform AOD distribution, and the largest spatial inhomogeneities and values $\tau_{550}>1$ were observed over the central part of Western Siberia on 24-28 July (Fig. 8 and Table 2).

The statistical characteristics in Table 2 were calculated using measurements from AQUA and TERRA platforms (MODIS collection 6, http://giovanni.sci.gsfc.nasa. gov/giovanni). These data suggest that, for three out of four periods considered here, the average AOD values at the Tomsk-22 site are close to spatio-temporal averages across the entire territory of Western Siberia: the difference between satellite and ground-based data is much less than between the standard deviations, except in the period of 24$28 \mathrm{July}$, when the average AOD at Tomsk-22 site was $\tau_{550}=$ 

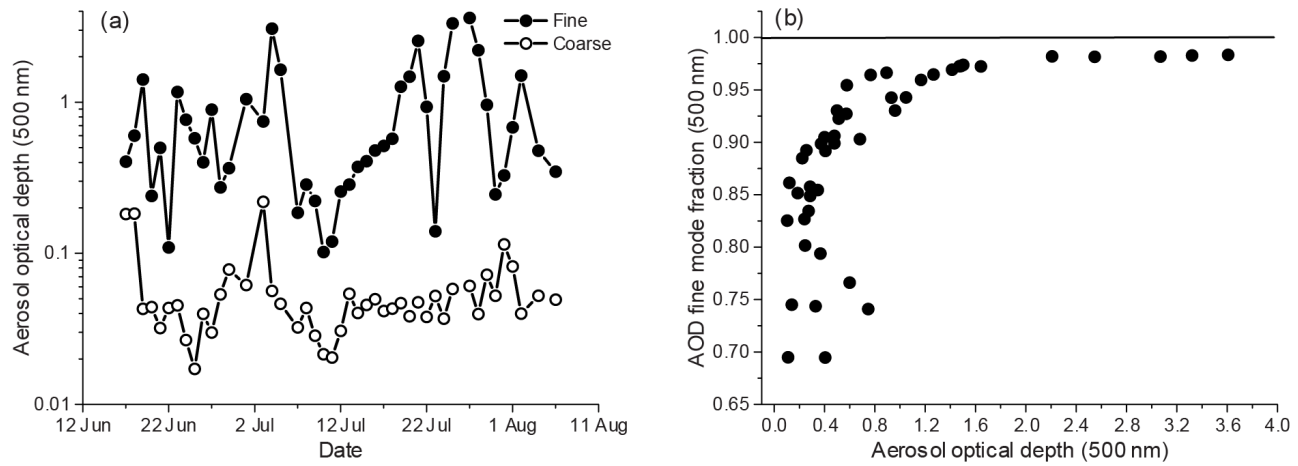

Figure 7. (a) Time series of computed average fine- and coarse-mode AOD, (b) fine-mode fraction of AOD as a function of AOD (500 nm) for the Tomsk data during extreme fires in 2012.
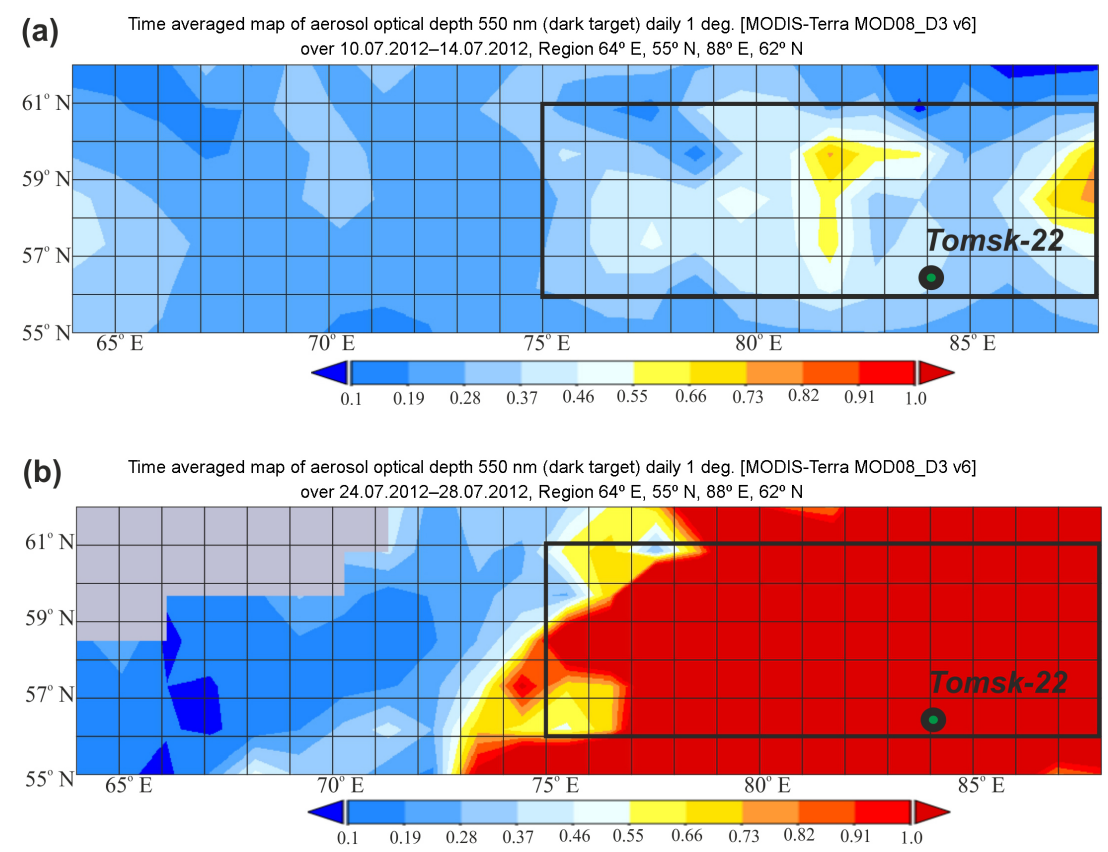

Figure 8. Spatial AOD distribution over the central part of Western Siberia according to MODIS data for summer 2012: (a) 10-14 July, (b) 24-28 July.

2.74 and exceeded the average value for Western Siberia (MODIS) $\tau_{550}=1.06$. At the same time, the satellite data in the $\left(1^{\circ} \times 1^{\circ}\right)$ region of Tomsk-22 site agree well with the results of photometric observations. Thus, the results of ground-based measurements in the region of Tomsk-22 can be considered to reflect not only the local AOD features, but also the regularities of variations for the entire territory of Western Siberia.

\subsection{Retrieval results}

We will compare the retrievals of aerosol optical and microphysical characteristics under the conditions of Siberian fires in 2012 against the average data for ordinary smoke (Table 3). Since the AOD dependence of $C_{\mathrm{v}}$ and $r_{\mathrm{v}}$ for fine- and coarse-mode aerosols has previously been noted for a wide variety of aerosol types (including biomass burning aerosol; Dubovik et al., 2002; Sayer et al., 2014), Table 3 also presents the resulting linear regression relationships between the pairs $\left(C_{\mathrm{v}}^{\mathrm{f}(\mathrm{c})}, \tau_{440}\right)$ and $\left(r_{\mathrm{v}}^{\mathrm{f}(\mathrm{c})}, \tau_{440}\right)$, as well as the corresponding linear correlation coefficient $R$.

\subsubsection{Volume size distributions}

During the extreme smoke, the average values of volume median radii for fine and coarse fractions were $r_{\mathrm{v}}^{\mathrm{f}}=0.18 \mu \mathrm{m}$ and $r_{\mathrm{v}}^{\mathrm{c}}=3.3 \mu \mathrm{m}$, a little larger than these characteristics for ordinary smoke, equalling 0.16 and $2.9 \mu \mathrm{m}$ respectively (Table 3 ). The $r_{\mathrm{v}}^{\mathrm{f}}$ value, in both cases, was in the range of values obtained for biomass burning in other regions of the globe (Reid 
Table 2. Average $( \pm \mathrm{SD})$, minimal, and maximal values of AOD $(550 \mathrm{~nm})$ in different periods of 2012 Siberian fires according to data from ground-based and satellite measurements over the central part of Western Siberia.

\begin{tabular}{lrrrrrr}
\hline & \multicolumn{2}{c}{ Satellite data } & & \multicolumn{2}{c}{$\begin{array}{c}\text { Ground-based observations } \\
\text { (Tomsk-22) }\end{array}$} \\
\cline { 2 - 3 } \cline { 6 - 7 } Period & Average $\pm \mathrm{SD}$ & $\min / \max$ & & Average \pm SD & $\min / \mathrm{max}$ \\
\hline 6-10 June & $0.23 \pm 0.08$ & $0.04 / 0.41$ & & $0.19 \pm 0.07$ & $0.10 / 0.27$ \\
1-4 July & $1.40 \pm 0.62$ & $0.18 / 3.25$ & & $1.51 \pm 1.05$ & $0.85 / 2.72$ \\
10-14 July & $0.28 \pm 0.11$ & $0.08 / 0.76$ & & $0.22 \pm 0.11$ & $0.11 / 0.35$ \\
24-28 July & $1.19 \pm 1.08$ & $0.00 / 3.63$ & & $2.74 \pm 1.07$ & $1.32 / 3.83$ \\
\hline
\end{tabular}

Table 3. Optical and microphysical properties of biomass burning aerosol retrieved from AERONET Tomsk sites (Tomsk, Tomsk-22).

\begin{tabular}{lll}
\hline Aerosol characteristics & Extreme smoke 2012 & Ordinary smoke 2003-2011, 2013 \\
\hline$n(440 / 675 / 870 / 1020)$ & $1.469 / 1.486 / 1.503 / 1.499$ & $1.454 / 1.471 / 1.485 / 1.499$ \\
$\kappa(440 / 675 / 870 / 1020),\left(\times 10^{2}\right)$ & $0.673 / 0.538 / 0.501 / 0.488$ & $1.126 / 1.005 / 1.057 / 1.06$ \\
$\omega(440 / 675 / 870 / 1020)$ & $0.96 / 0.96 / 0.95 / 0.95$ & $0.92 / 0.91 / 0.89 / 0.88$ \\
$g(440 / 675 / 870 / 1020)$ & $0.68 / 0.59 / 0.54 / 0.51$ & $0.68 / 0.59 / 0.55 / 0.54$ \\
$r_{\mathrm{v}}^{\mathrm{f}}(\mu \mathrm{m}), \sigma^{\mathrm{f}}(\mu \mathrm{m})$ & $0.181 \pm 0.02 ; 0.507 \pm 0.058$ & $0.161 \pm 0.030 ; 0.422 \pm 0.058$ \\
& $r_{\mathrm{v}}^{\mathrm{f}}=0.166+0.017 \tau_{440}(R=0.47)$ & $r_{\mathrm{v}}^{\mathrm{f}}=0.153+0.011 \tau_{440}(R=0.13)$ \\
$r_{\mathrm{v}}^{\mathrm{c}}(\mu \mathrm{m}), \sigma^{\mathrm{c}}(\mu \mathrm{m})$ & $3.321 \pm 0.365 ; 0.703 \pm 0.056$ & $2.911 \pm 0.665 ; 0.694 \pm 0.077$ \\
& $r_{\mathrm{v}}^{\mathrm{c}}=2.928+0.44 \tau_{440}(R=0.66)$ & $r_{\mathrm{v}}^{\mathrm{c}}=3.10-0.249 \tau_{440}(R=-0.13)$ \\
$C_{\mathrm{v}}^{\mathrm{f}}\left(\mu \mathrm{m}^{3} \mu \mathrm{m}^{-2}\right)$ & $0.11 \pm 0.065$ & $0.097 \pm 0.042$ \\
& $C_{\mathrm{v}}^{\mathrm{f}}=0.009+0.114 \tau_{440}(R=0.96)$ & $C_{\mathrm{v}}^{\mathrm{f}}=0.017+0.106 \tau_{440}(R=0.87)$ \\
$C_{\mathrm{v}}^{\mathrm{c}}\left(\mu \mathrm{m}^{3} \mu \mathrm{m}^{-2}\right)$ & $0.025 \pm 0.012$ & $0.062 \pm 0.04$ \\
& $C_{\mathrm{v}}^{\mathrm{c}}=0.013+0.014 \tau_{440}(R=0.62)$ & $C_{\mathrm{v}}^{\mathrm{c}}=0.036+0.035 \tau_{440}(R=0.24)$ \\
\hline
\end{tabular}

et al., 2005a, b; Eck et al., 2009; Chubarova et al., 2012), as well as in the range of measurements for aged smoke, performed using an optical particle counter $(0.1-3 \mu \mathrm{m})$ and a differential mobility particle sizer $(0.01-0.6 \mu \mathrm{m})$ in the boreal zones of Europe and North America (Reid et al., 2005a). As in Siberia, a wider size distribution of fine particles than for ordinary smoke (Table 3; Fig. 3d) was also noted by other authors for severe fires in the boreal zone of Alaska (Bonanza Creek, 2004-2005, Eck et al., 2009).

The noteworthy salient features of fine aerosol fraction during summer 2012 are as follows. The contribution of fine fraction to the total volume $\left(C_{\mathrm{v}}^{\mathrm{f}} / C_{\mathrm{v}}^{\mathrm{t}}\right)$, on average, increased to $0.8 \pm 0.065$ compared to the value $0.65 \pm 0.21$ according to multi-year observations. Volume concentrations and volume median radii of the fine mode are plotted in Fig. 9a as functions of AOD at $440 \mathrm{~nm}$. This figure shows that there is a general increase in volume concentrations $C_{\mathrm{v}}^{\mathrm{f}}$ as $\tau_{440}$ increases (Fig. 9a). The median radius of the fine mode increased from about 0.15 to $0.22 \mu \mathrm{m}$ as $\tau_{440}$ changed from 0.4 to 1.5 and larger (Fig. 9b). The smoke particles have large radii, and $r_{\mathrm{v}}^{\mathrm{f}}$ and $\tau_{440}$ are closely correlated, possibly because of a high concentration of aerosol, which leads to greater coagulation, condensation, and gas-to-particle conversion (Reid et al., 1998, 2005a; Eck et al., 2009). From this figure it also follows that the interrelation between median radius of fine aerosol fraction and AOD at $440 \mathrm{~nm}$ in ordinary smoke is much less pronounced, primarily because of the variety of properties of biomass burning aerosol combined in this data set. For instance, in May 2004, the median radius was relatively small $\left(r_{\mathrm{v}}^{\mathrm{f}} \sim 0.14 \mu \mathrm{m}\right)$ and did not practically change with varying $\tau_{440}$. Most probably, this was because the burning of the previous year's vegetation was one of the sources of smoke particles in this period of time. An analogous feature was also observed during African savanna fires (Dubovik et al., 2002).

In contrast to data from multi-year observations, in summer 2012 an increase in the volume concentration and median radius of the coarse mode was observed with growing AOD. Most probably, soil particles, having been suspended by saltation of surface dust driven by fire generated winds, were also present during this period of time in the composition of coarse mode in addition to carbon aggregates.

Results of retrieval of disperse composition of finemode aerosol in the atmospheric column agree with measurements in the near-ground layer (Kozlov et al., 2014). Data from spectral-polarization nephelometric measurements were used to show that the volume median radius of the fine mode under the conditions of weak turbidity of the atmosphere (10-13 July 2012) increased from 0.1 to 0.4 $0.5 \mu \mathrm{m}$ when smoke plumes intruded into the region of observations (25-29 July 2012). 

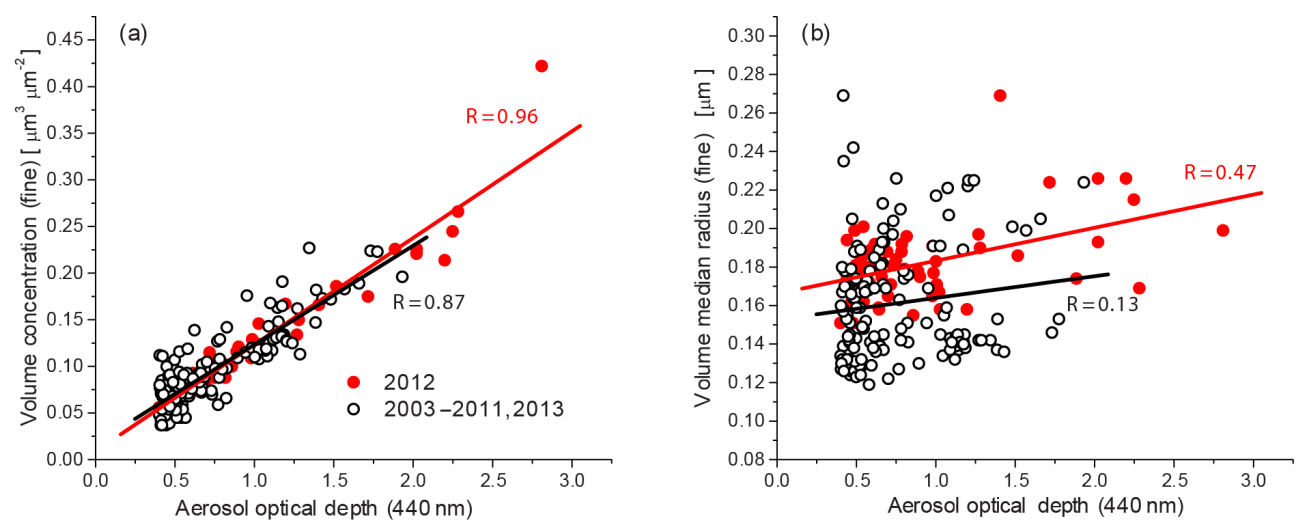

Figure 9. (a) Fine-mode volume concentration and (b) median radius vs. $\mathrm{AOD}(440 \mathrm{~nm})$ in Tomsk.

\subsubsection{Refractive index}

Average values of the real and imaginary parts of the refractive index in extreme and ordinary smoke are presented in Table 3. In ordinary smoke, the imaginary part of the refractive index $\kappa_{\lambda}$ changes weakly with increasing wavelength and is approximately 0.01 . However, the imaginary refractive index during smoke pollution in 2012 shows low values and relatively large decrease in $\kappa_{\lambda}$ as the wavelength grows from 440 to $675 \mathrm{~nm}$. The $\kappa_{\lambda}$ variations in the wavelength interval of $675-1020 \mathrm{~nm}$ are not so large.

The quantitative differences and specific features of spectral dependence of the imaginary refractive indices stem from different properties of atmospheric carbonaceous particles, i.e. black carbon (BC) and organic aerosol (OA). Recent studies showed that OA components can contribute substantially to light absorption. In contrast to $\mathrm{BC}$, which absorbs light throughout the UV-visible spectrum, an OA component such as brown carbon $(\mathrm{BrC})$ absorbs mostly at the ultraviolet wavelengths and less significantly in the visible spectral range (Kirchstetter et al., 2004; Bergstrom et al., 2007; Chen and Bond, 2010; Zhong and Jang, 2014; Chakrabarty et al., 2016). The majority of $\mathrm{BrC}$ is emitted to the atmosphere through low temperature, incomplete combustion of biomass, bio- and fossil fuel (Bond, 2001; Kirchstetter et al., 2004; Bergstrom et al., 2007; Lewis et al., 2008; Chen and Bond, 2010; Zhong and Jang, 2014).

The absorption efficiency and spectral dependence vary depending on the type of $\mathrm{BrC}$ origin. $\mathrm{Lu}$ et al. (2015) reviewed available measurements (laboratory and field observations) of light-absorbing primary organic aerosols, and quantify the wavelength-dependent imaginary refractive indices $\left(\kappa_{\mathrm{OA}}\right)$ for the bulk primary $\mathrm{OA}$ emitted from biomass/biofuel, lignite, propane, and oil combustion sources. Based on generalized information, they suggested parameterizing $\kappa_{\mathrm{OA}}$ of biomass/biofuel combustion sources as a function of BC-to-OA ratio. Analysis of imaginary refractive indices showed the stronger wavelength-dependent $\kappa_{\mathrm{OA}}$ for lower BC-to-OA ratio conditions (smoldering com-

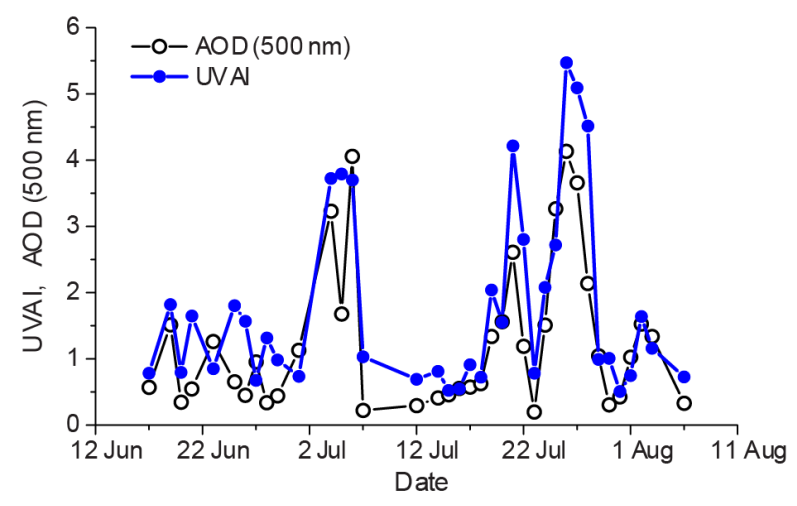

Figure 10. Ultraviolet aerosol index (http://giovanni.sci.gsfc.nasa. gov/giovanni/) near Tomsk $\left(55-57^{\circ} \mathrm{N}, 83-85^{\circ} \mathrm{E}\right)$ and AOD according to data from ground-based measurements (http://aeronet.gsfc. nasa.gov).

bustion), while the greater $\kappa_{\mathrm{OA}}$ values at $\lambda>350 \mathrm{~nm}$ are observed for higher BC-to-OA ratio (flaming combustion).

These results allow us to hypothesize that the reason for the $\kappa_{\lambda}$ decrease in the interval of $440-675 \mathrm{~nm}$ during summer 2012 may be due to the contribution of compounds absorbing radiation in UV wavelength region (brown carbon). To confirm this hypothesis, we considered OMI (Ozone Monitoring Instrument) observations of the ultraviolet aerosol index (UVAI), the value of which is sensitive to aerosol absorption in the ultraviolet wavelength region (Torres et al., 1998; Jethva and Torres, 2011; Hammer et al., 2016). Satellite data indicate that UVAI values were quite high during the smoke pollution in 2012, and exceeded 4-5 on individual days, thus explaining the above-mentioned $\kappa_{\lambda}$ decrease from UV to the visible spectral region (Fig. 10).

The relatively constant imaginary refractive index in ordinary smoke is due to averaging over many situations and differs, in particular, in the type of burning biomass (peat, forest, grass). For instance, in May 2004, when the characteristics of smoke aerosol were quite homogeneous, the av- 

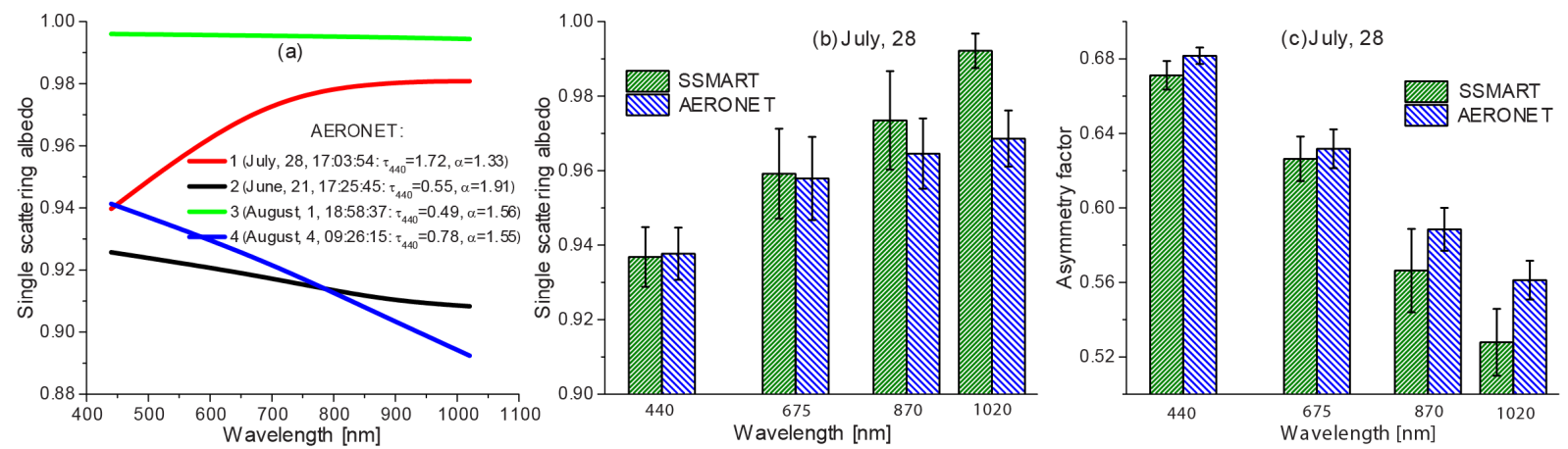

Figure 11. (a) Examples of spectral dependence of single scattering albedo (Dubovik and King, 2000), and diurnally averaged spectral variations of SSMART- and AERONET-derived (b) single scattering albedo and (c) asymmetry factor for 28 July 2012; error bars indicate the standard deviations.

erage spectral behaviour of $\kappa_{\lambda}$ was weakly manifested, with $\kappa_{\lambda} \approx 0.013$ in the interval of $440-1020 \mathrm{~nm}$. At the same time, the UVAI value did not exceed 1.2 (http://giovanni.sci.gsfc. nasa.gov/giovanni/), suggesting that $\mathrm{BC}$ was seemingly the main absorbing substance in this period of time.

\subsubsection{Single scattering albedo and asymmetry factor}

The main results, presented in this section, were obtained using the algorithm from Dubovik and King (2000). At the same time, we present the SSA and AF values, retrieved using our SSMART algorithm in separate atmospheric conditions. The SSA and AF values were retrieved directly from the data from AOD and sky radiance measurements through solution of radiative transfer equation (Way 1 , Bedareva et al., 2013a, 2014).

\section{Cases of study}

Detailed analysis of spectral SSA in 2012 has revealed two types of dependence: monotonically decreasing and monotonically increasing $\omega_{\lambda}$ with growing wavelength (Fig. 11a).

The main group of SSA data ( 45 cases out of 65 ) is characterized by a weakly decreasing spectral dependence: the range of the differences $\Delta \omega_{\lambda}=\omega_{440}-\omega_{1020}$ did not exceed 0.03. Practically all sets of retrieved SSA of this type lie between curves $2\left(\omega_{440}=0.926\right)$ and $3\left(\omega_{440}=0.996\right)$. In other cases, the $\omega_{\lambda}$ decrease with growing wavelength is larger, but does not exceed 0.06 (curve 4, Fig. 11a). We note that the values of the imaginary part of the refractive index are $\sim 0.006$ for this subset of data. In a few (14 out of 65) situations with high atmospheric turbidities $\left(\tau_{440}>0.9\right)$, there was an increase in SSA with growing wavelength (curve 1 in Fig. 11a). The monotonic increase in $\omega_{\lambda}$ agrees with a decrease in $\kappa_{\lambda}$ (on average, from 0.01 at $440 \mathrm{~nm}$ to $\sim 0.006$ at $675 \mathrm{~nm}$ ), presumably due to additional absorption of brown carbon in the UV wavelength region.

We will compare the single scattering albedo and asymmetry factor, retrieved using AERONET and SSMART al- gorithms (Table 4, Fig. 11b, c). Table 4 presents the $\omega_{\lambda}$ and $g_{\lambda}$ values for three individual atmospheric conditions. These data illustrate that both approaches ensure a consistent spectral behaviour of SSA: the increase (28 July) and decrease (4 August) of the single scattering albedo with growing wavelength, as well as a near-neutral spectral dependence of SSA (1 August). The difference in $\omega_{\lambda}$ values in these examples does not exceed 0.03 and is within the uncertainty of retrieval estimates of both algorithms. The difference in asymmetry factor is $\sim 0.03$, increasing to 0.05 at $\lambda=1020 \mathrm{~nm}$.

The reason for the differences in the optical characteristics may be the following circumstances. When measurements of solar radiation in solar almucantar are used in the solution of the inverse problem with the help of the SSMART algorithm (Way 1), the scattering phase function of aerosol particles $g_{\mathrm{a}}(\theta)$ can be retrieved only in the region of scattering angles $\theta \leq 2 \theta_{0}\left(\theta_{0}\right.$ is the solar zenith angle); while in the remaining angular range the values of aerosol scattering phase function are extrapolated. The extrapolation procedure may lead to relatively large (larger than 20-30\%) uncertainties of $g_{\mathrm{a}}(\theta)$ retrieval for $\theta>2 \theta_{0}$, and may influence the accuracy of the retrieval of the asymmetry factor and, to a lesser degree, the single scattering albedo. We discussed these issues in our earlier work (Bedareva and Zhuravleva, 2011). Another reason for the differences may be the fact that the SSMART algorithm retrieves the optical characteristics for each spectral channel singly, rather than calculating them for all channels simultaneously on the basis of retrieved complex refractive index and particle size spectrum, as the AERONET algorithm makes. Therefore, the results of the solution of the inverse problem with the use of the algorithm from Dubovik and King (2000) are characterized by more consistent spectral dependence of SSA and AF compared to the SSMART software package.

We will consider the results of retrieval of single scattering albedo and asymmetry factor from 28 July 2012 (Fig. 11b, c). The solutions of the inverse problem, based on application 
Table 4. Single scattering albedo and asymmetry factor, retrieved using the AERONET algorithm and SSMART software package.

\begin{tabular}{|c|c|c|c|c|c|c|c|c|c|}
\hline \multicolumn{10}{|c|}{ Single scattering albedo } \\
\hline \multirow[b]{2}{*}{ Date } & \multirow[b]{2}{*}{ Time } & \multicolumn{4}{|c|}{ AERONET } & \multicolumn{4}{|c|}{ SSMART } \\
\hline & & 440 & 675 & 870 & 1020 & 440 & 675 & 870 & 1020 \\
\hline $28 \mathrm{Jul}$ & $17: 03$ & 0.940 & 0.975 & 0.981 & 0.981 & 0.940 & 0.976 & 0.998 & 0.999 \\
\hline 1 Aug & $18: 58$ & 0.996 & 0.996 & 0.995 & 0.994 & 0.972 & 1.0 & 1.0 & 1.0 \\
\hline 4 Aug & $09: 26$ & 0.941 & 0.924 & 0.906 & 0.892 & 0.956 & 0.947 & 0.934 & 0.911 \\
\hline \multicolumn{10}{|c|}{ Asymmetry factor } \\
\hline & & \multicolumn{4}{|c|}{ AERONET } & \multicolumn{4}{|c|}{ SSMART } \\
\hline Date & Time & 440 & 675 & 870 & 1020 & 440 & 675 & 870 & 1020 \\
\hline $28 \mathrm{Jul}$ & $17: 03$ & 0.682 & 0.625 & 0.581 & 0.554 & 0.663 & 0.618 & 0.552 & 0.513 \\
\hline 1 Aug & $18: 58$ & 0.699 & 0.619 & 0.568 & 0.548 & 0.713 & 0.631 & 0.545 & 0.515 \\
\hline 4 Aug & $09: 26$ & 0.659 & 0.585 & 0.545 & 0.529 & 0.659 & 0.568 & 0.518 & 0.488 \\
\hline
\end{tabular}

of two independent approaches, agree not only qualitatively but also quantitatively. At the same time, the daily average SSA (AF) values, retrieved using the SSMART algorithm, are overestimated (underestimated) relative to AERONET data by about 0.01 , except for $\lambda=1020 \mathrm{~nm}$, when the differences increase to 0.02 and 0.04 respectively.

The consistency of results can be considered as an indirect evidence that the spectral SSA dependence, atypical for the smoke aerosol, is not so much due to methodic features of retrieval procedures, but to specific features of smoke aerosol over the AERONET site in Tomsk on 28 July (possibly, chemical composition and particle sizes). In Sect. 4.2.2 we hypothesized that the increased absorption by aerosol particles in the ultraviolet spectral range may be due to the presence of brown carbon; indeed, the largest value UVAI $=4$ 6 over the entire period of extreme smoke was observed on 26-28 July (Fig. 10). However, the limited data set considered in this work still does not allow us to explain the observed spectral behaviour of SSA. We can now only state that the increase in the single scattering albedo with growing wavelength was observed not only in Tomsk, but also in certain situations during severe fires in Moscow during 2010 and in Alaska during 2004 (http://aeronet.gsfc.nasa.gov). In addition, the laboratory analysis showed that brown carbon, with a negligible amount of black carbon, predominated in the composition of aerosol particles emitted from the burning of Alaskan and Siberian peatlands (Chakrabarty et al., 2016). A more detailed analysis of the spectral dependence of SSA of smoke aerosol under the conditions of extraordinary fires will be the subject of further studies.

\section{Comparison of Tomsk extreme and ordinary smoke to other boreal biomass burning sites}

On the whole, the period of strong fires in Tomsk was characterized by weak spectral variations in SSA, the average being $\sim 0.96$, consistent with previous results in other regions of the Eurasian boreal zone, e.g. in Moscow (2002 and 2010) and Alaska (2004-2005), where the smoldering phase prevailed over the flaming fire phase (Eck et al., 2009; Chubarova et al., 2011; Sayer et al., 2014) (Fig. 12a). The relatively constant spectral single scattering albedo during extreme smoke in 2012 may be also partly due to growth of aerosol particle sizes (Sect. 4.2.1, Table 3; see also Eck et al., 2009).

The SSA retrievals in the atmospheric column satisfactorily agree with data in the ground-layer (Kozlov et al., 2014), according to which the single scattering albedos in the visible range $(\lambda=510 \mathrm{~nm})$ were in the interval of $0.95-0.98$. At the same time, the imaginary and real parts of the complex refractive index of dry base of substance varied in the ranges of 0.01-0.02 and 1.36-1.47 respectively.

The overwhelming majority of results of individual retrievals in ordinary smoke also showed a monotonic SSA decrease with the increasing wavelength, with the opposite dependence being observed in only 6 cases out of 140 . However, in contrast to extreme smoke, the spectral SSA behaviour was more pronounced: $\Delta \omega_{\lambda}$ reached $0.06-0.18$ in $18 \%$ of cases; $\Delta \omega_{\lambda}$ was $0.03-0.06$ in $40 \%$ of cases, and $\Delta \omega_{\lambda}$ was less than 0.03 in $34 \%$ of cases.

The average single scattering albedos in ordinary smoke, presented in Fig. 12a, turned out to be about 0.02 lower than those observed in the boreal forests of USA and Canada (Dubovik et al., 2002). These differences may be due to both methodic and physical factors. Methodic-type differences might stem from different methods for selecting the smoke conditions. The specific features of the spectral dependence of SSA can also be explained by different combinations of the composition and age of smoke aerosol, which were recorded at AERONET observation sites. This is clearly illustrated by results obtained in May 2004 in Tomsk (Fig. 12a). Lower values and pronounced spectral variations 

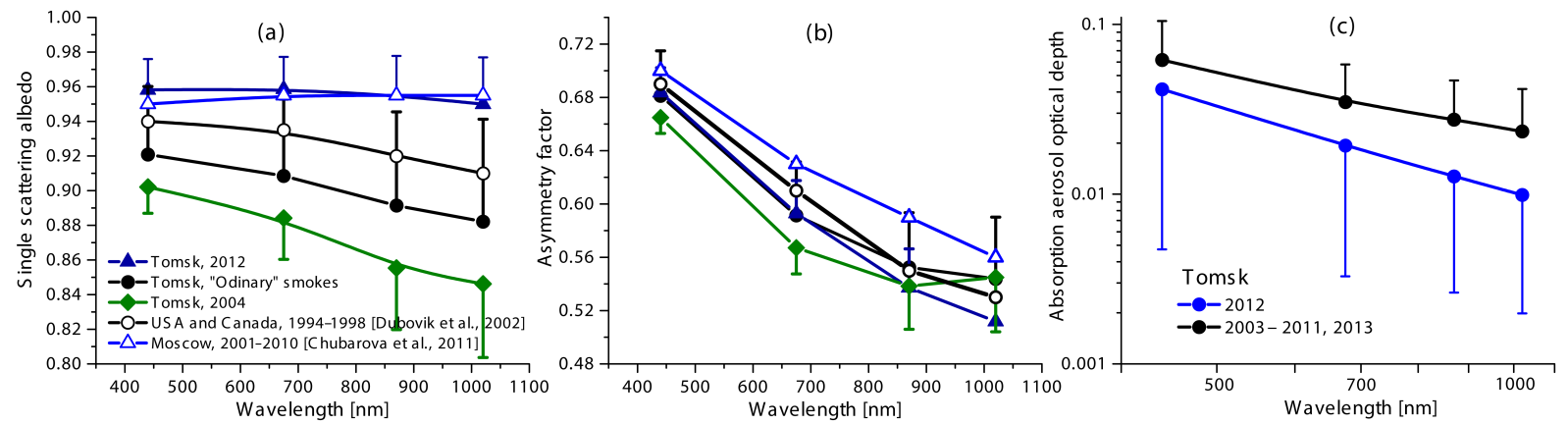

Figure 12. Average (a) SSA and (b) AF for different periods and regions of observations and (c) average spectral absorption aerosol optical depth for 2012 extreme and ordinary smoke; the error bars indicate the standard deviations. One-sided error bars are used in order not to overburden the figures.

of SSA (a decrease from 0.9 to 0.85 ) may be due to the previous year's grass and agricultural vegetation combustion products present in the smoke composition, as well as due to a flaming phase of combustion which predominated in that period of time. Close values and analogous spectral dependence of single scattering albedo were also noted in African savanna fires in Zambia (Dubovik et al., 2002; Sayer et al., 2014).

Aerosol absorption optical depth $\tau_{\mathrm{abs}, \lambda}$ and absorption Ångström exponent $\alpha_{\mathrm{abs}}$, computed for the spectral interval of 440-870 nm (Sect. 2), were considered as other characteristics of absorbing properties of aerosol particles.

Data presented in Fig. 12c show that the average values of $\tau_{\mathrm{abs}, \lambda}$ during strong fires in 2012 were about a factor of $1.5-2$ smaller than for ordinary smoke. In addition, there are differences in $\alpha_{\mathrm{abs}}$, which are $1.6 \pm 0.44$ for extreme smoke and $1.2 \pm 0.5$ for ordinary smoke.

The AAE values can be used as an indicator of aerosol composition (Andreae and Gelencsér, 2006; Russell et al., 2010; Schuster et al., 2016). The relatively low values $\alpha_{\mathrm{abs}} \sim 1$ are typical for aerosol absorption largely dominated by black or light absorbing carbon, while larger values suggest absorption by different material organic carbon (Bergstrom et al., 2002, 2007; Kirchstetter et al., 2004; Lewis et al., 2008; Russell et al., 2010; Schuster et al., 2016). The $\alpha_{\text {abs }}$ increase in the 2012 fires may indicate that, on average, smoke absorption possibly shifted from domination by black carbon in ordinary smoke to an increasing influence of absorption by other materials, most likely organic carbon (see also Fig. 10).

In contrast to single scattering albedo, the spectral asymmetry factor differs insignificantly among the 2012 fires, ordinary smoke, and May 2004 smoke (Table 3, Fig. 12b).

\section{Radiative effects of smoke aerosol}

The radiative effects of smoke aerosol were accounted for by calculating the transmittance $(T)$, albedo $(A)$, and absorp- tance of the atmosphere $\left(\mathrm{ABS}_{\mathrm{ATM}}\right)$ and underlying surface $\left(\mathrm{ABS}_{\mathrm{SUR}}\right)$ :

$$
\begin{aligned}
& T=100 \% \times F_{\mathrm{BOA}}^{\downarrow} / F_{\mathrm{TOA}}^{\downarrow}, A=100 \% \times F_{\mathrm{TOA}}^{\uparrow} / F_{\mathrm{TOA}}^{\downarrow}, \\
& \mathrm{ABS}_{\mathrm{ATM}}=100 \% \times\left(F_{\mathrm{TOA}}^{\text {net }}-F_{\mathrm{BOA}}^{\text {net }}\right) / F_{\mathrm{TOA}}^{\downarrow}, \\
& \mathrm{ABS}_{\mathrm{SUR}}=100 \% \times F_{\mathrm{BOA}}^{\text {net }} / F_{\mathrm{TOA}}^{\downarrow} .
\end{aligned}
$$

Here, $F_{\mathrm{BOA}(\mathrm{TOA})}^{\downarrow(\uparrow)}$ are broadband solar radiative fluxes in the interval of $(0.2-5 \mu \mathrm{m})$, the symbols $\downarrow(\uparrow)$ are used to denote the downward and upward radiation at the TOA and BOA. Radiative influxes $F^{\text {net }}$ at different levels are calculated as follows.

$$
F_{\mathrm{BOA}(\mathrm{TOA})}^{\mathrm{net}}=F_{\mathrm{BOA}(\mathrm{TOA})}^{\downarrow}-F_{\mathrm{BOA}(\mathrm{TOA})}^{\uparrow}
$$

The results of radiative flux simulation were used to calculate the direct radiative effect (DRE) at TOA and BOA and in atmospheric column:

$$
\begin{aligned}
& \Phi_{\mathrm{TOA}(\mathrm{BOA})}=F_{\mathrm{TOA}(\mathrm{BOA})}^{\text {net,a }}-F_{\mathrm{TOA}(\mathrm{BOA})}^{\text {net, }}, \\
& \Phi_{\mathrm{ATM}}=\Phi_{\mathrm{TOA}}-\Phi_{\mathrm{BOA}},
\end{aligned}
$$

where superscript "a" and " $\mathrm{R}$ " correspond to the calculations in aerosol-molecular atmosphere and in the aerosol-free atmosphere, with only molecular (Rayleigh) scattering and absorption taken into consideration. The negative and positive DRE values are associated with an aerosol cooling and warming, both at TOA and BOA. In addition to the proper DRE, we also considered the radiative effect efficiency:

$$
\Phi_{\mathrm{TOA}(\mathrm{BOA})}^{\mathrm{e}}=\Phi_{\mathrm{TOA}(\mathrm{BOA})} / \tau_{550}, \quad \Phi_{\mathrm{ATM}}^{\mathrm{e}}=\Phi_{\mathrm{ATM}} / \tau_{550},
$$

which characterizes the rate at which the atmosphere is forced per unit of AOD at $550 \mathrm{~nm}$. The $\Phi^{\mathrm{e}}$ value depends on reflective properties of underlying surface, size distribution of aerosol particles, and their chemical composition. It also depends on AOD to some extent (due to the multiple scattering effects). 


\subsection{Model and input data}

The broadband fluxes of the solar radiation in the molecularaerosol plane-parallel atmosphere were calculated using the algorithm from the Monte Carlo method, which we developed earlier (Zhuravleva et al., 2009). The radiative fluxes at a given atmospheric level $z$ are represented as a sum of fluxes in separate spectral intervals:

$F^{\downarrow(\uparrow)}(z)=\sum_{i=1}^{M} F_{i}^{\downarrow(\uparrow)}(z)$

where $M=31$ is the number of bands $\Delta \lambda=\left(\lambda_{i}, \lambda_{i+1}\right), i=$ $1, \ldots M-1, \lambda_{1}=0.2 \mu \mathrm{m}, \lambda_{M}=5.0 \mu \mathrm{m}$. Within each subinterval, the optical characteristics of aerosol and molecular scattering coefficient are assumed to be constant and equal to their values in the middle of the subinterval. The transmission function is approximated by a finite exponential series (k-distribution method). The algorithm intrinsically takes into account the multiple scattering, absorption by aerosol and molecular particles, as well as the reflection of incident radiation from the underlying surface according to Lambert's law. The comparisons showed that the numerical simulation results are in a satisfactory agreement with results of line-byline calculations and data from field measurements (Tvorogov et al., 2008; Zhuravleva et al., 2009, 2014).

The spectral AOD (340-1020 nm), the water vapour content, the column-integrated single scattering albedo, and the asymmetry parameter taken from AERONET were used as the main input parameters of the algorithm under the smoke conditions. In the interval of 440-1020 nm, the spectral values $\omega_{\lambda}$ and $g_{\lambda}$ have been linearly interpolated from the values of SSA and AF retrieved at the four AERONET inversion wavelengths, while for $\lambda \leq 440 \mathrm{~nm}$ and $\lambda \geq 1020 \mathrm{~nm}$ they have been considered constant, similar to García et al. (2012) and Panchenko et al. (2012). Under the background conditions, Level-2.0 retrieval products for the single scattering albedo and asymmetry factor, obtained on the basis of standard AERONET algorithm, are not available due to low AOD values $\left(\tau_{550}=0.13\right.$ according to data from multi-year ground-based measurements under summer conditions, Sakerin et al., 2009; Sakerin and Kabanov, 2015). Therefore, the OPAC model (averaged continental aerosol, relative air humidity is $70 \%$; Hess et al., 1998) was used to simulate the radiative characteristics under the conditions of the weakly turbid atmosphere.

As in Panchenko et al. (2012), the aerosol optical depth was assumed to be constant outside the wavelength interval of $340-1020 \mathrm{~nm}: \tau(\lambda \leq 340 \mathrm{~nm})=\tau_{340}$, $\tau(\lambda \geq 1020 \mathrm{~nm})=\tau_{1020}$. Such an approach was chosen for the following reasons. The contribution of solar radiation, incoming at TOA in the interval of $200-340 \mathrm{~nm}$, is about $3.5 \%$; therefore, in the absence of measurements, the specified character of spectral dependence of AOD cannot significantly influence the simulation results. Based on the data from multi-year ground-based observations in Siberia, Sakerin and Kabanov (2007) showed that AOD hardly varies in the interval $\lambda>1000 \mathrm{~nm}$; therefore, we can assume that $\tau(\lambda>1000 \mathrm{~nm}) \sim \tau(\lambda \sim 1000 \mathrm{~nm})$.

The molecular absorption coefficients were calculated on the basis of the HITRAN2008 database and MT_CKD v.2.4 continuum model (http://rtweb.aer.com/continuum_frame. $\mathrm{html}$ ) using a regional model of temperature, pressure, and water vapour concentration profiles (Komarov and Lomakina, 2008) and taking into account the absorption by all the atmospheric gases which were presented in the AFGL meteorological model (Anderson et al., 1986). The profiles of ozone $\mathrm{O}_{3}$ and carbon dioxide $\mathrm{CO}_{2}$ were specified taking into consideration the data from multi-year observations, obtained in Western Siberia during summer. The total $\mathrm{O}_{3}$ content was taken to be equal to $340 \mathrm{DU}$ (according to data from TOMS (Total Ozone Mapping Spectrometer) satellite instrumentation, 2000-2010) and the $\mathrm{CO}_{2}$ mixing ratio was taken to be equal to $380 \mathrm{ppm}$ (according to data from aircraft sensing in 1997-2007; Arshinov et al., 2009).

It is well known that the surface albedo affects (primarily upward) radiative fluxes and may even cause DRE sign reversal (see e.g. Zhuravleva and Sakerin, 2009; García et al., 2012; Tomasi et al., 2015). The processes of soot sedimentation on the ground and appearance of blanked patches from burning produce changes in the surface reflectance and possible variations in the radiative characteristics of the atmosphere. A detailed discussion of these problems is beyond the scope of the present work; therefore, all calculations below were performed for the same surface albedos $A_{\mathrm{s}, \lambda}$, specified using multi-year data from MODIS satellite measurements for the region of Tomsk in June-August (Moody et al., 2005).

Data from Fontenla et al. (1999) were used to account for the spectral behaviour of the solar constant.

The applicability of the algorithm and the approach to specifying the set of input parameters were confirmed by our earlier results of the complex radiation experiments (Zhuravleva et al., 2009, 2014).

\subsection{Simulation results}

Recent studies showed that considering only a specific spectral range of aerosol properties and neglecting uncertainties when specifying the input parameters (aerosol optical characteristics, surface albedo, total content, and vertical profiles of concentrations of atmospheric gases, etc.) may result in important error sources in estimates of aerosol radiation effects (Myhre et al., 2003; Zhou et al., 2005; García et al., 2008, 2012; Zhuravleva et al., 2009; Zhuravleva and Sakerin, 2009). The magnitude of these errors depends mainly on aerosol type (background continental, oceanic, biomass burning, urban-industrial, desert dust, etc.), reflection model, and albedo of underlying surface, as well as on solar zenith angle (see e.g. García et al., 2008, 2012, 2014; Zhuravleva and Sakerin, 2009). 
Table 5. Parameters of radiation calculations.

\begin{tabular}{llrrrrr}
\hline & \multicolumn{1}{c}{ Case } & $\tau_{550}$ & $\alpha_{440-870}$ & $W$ & $\omega_{550}$ & $g_{550}$ \\
\hline 1 & Background aerosol & 0.13 & 1.46 & 2.1 & 0.925 & 0.7 \\
2 & Ordinary smoke & 0.33 & 1.59 & 1.9 & 0.92 & 0.64 \\
3 & Extreme smoke 2012 & 0.84 & 1.58 & 2.2 & 0.96 & 0.64 \\
4 & 14 July & 0.34 & 1.74 & 2.5 & 0.98 & 0.64 \\
5 & 27 July & 3.54 & 1.54 & 1.2 & 0.94 & 0.65 \\
\hline
\end{tabular}

Spectral surface albedo: $A_{\mathrm{s}, 470}=0.036 ; A_{\mathrm{s}, 550}=0.067 ; A_{\mathrm{s}, 670}=0.068 ; A_{\mathrm{s}, 870}=0.251 ;$ $A_{\mathrm{s}, 1250}=0.285 ; A_{\mathrm{s}, 1650}=0.196 ; A_{\mathrm{s}, 2150}=0.1$.

In this work, we present the diurnally average radiative effects for five different situations (Table 5). To correctly estimate their uncertainties, it is necessary to take into account both variations in the characteristics of the atmosphere and underlying surface during the day and the dependence of uncertainties on the solar zenith angle. The estimates, presented in the literature, were generally obtained for fixed illumination conditions (see e.g. García et al., 2008, 2012, 2014; Zhuravleva and Sakerin, 2009), while uncertainty estimates for diurnally average radiative effects are scarce (see e.g. Tomasi et al., 2015, Esteve et al., 2016). In this work, we restrict ourselves to a discussion of radiation effects in different situations. The issue of what is the magnitude of uncertainty due to inaccurate information on input parameters of the problem needs additional numerical experiments.

Average values of AOD, W, SSA, and AF, which reflect the average radiative effects of smoke and background aerosol, were chosen as input parameters for the first three cases. In order to avoid the effect of the astronomical factor, the instantaneous values of $F_{\mathrm{TOA}(\mathrm{BOA})}^{\downarrow(\uparrow)}$ were calculated for the period between sunrise and sunset on 15 July for the latitude of Tomsk $\left(56^{\circ} \mathrm{N}\right)$. Cases 4 and 5 correspond to the conditions of strong (27 July) and relatively weak (14 July) aerosol turbidity and, as such, make it possible to estimate the variability range of radiative characteristics in the period of strong Siberian fires.

Figure 13 shows how radiation characteristics of the atmosphere and the underlying surface are redistributed under different conditions.

The atmospheric transmittance (hence $\mathrm{ABS}_{\mathrm{SUR}}$ ) was maximal $(71 \%)$ under the background conditions. The appearance of optically dense smoke cloud caused $T$ to decrease to $60 \%$ (Case 3). Immediately in the period of extreme smoke, the $T$ value varied from $67 \%$ (14 July) to $37 \%$ (27 July), being almost a factor of two smaller in the latter case than under the background conditions. Data from calculations agree with results of measurements of total radiative fluxes in Tomsk (Sklyadneva et al., 2015), which indicated that on 27 July 2012 the total radiation decreased by about $50 \%$ relative to the usual conditions. Atmospheric albedo was also maximal $(34 \%)$ on this day.

In an analysis of $\mathrm{ABS}_{\mathrm{ATM}}$, the existence of two competing factors should be taken into consideration. If we represent the atmospheric absorption as a series in the order of scattering, its $n$th term will be proportional to $\omega_{\lambda}^{n-1}\left(1-\omega_{\lambda}\right)$ and for large $\omega_{\lambda}$ the contribution of high orders of scattering will be significant. Therefore, AOD increase (and, consequently, increment in the average order of scattering) favours absorption growth due to the contribution of high orders of scattering. At the same time, large SSA values act as a factor reducing the atmospheric absorptance.

The $\mathrm{ABS}_{\mathrm{ATM}}$ value, calculated with averaged parameters, increased from $22 \%$ (Case 1) to $26 \%$ (Case 3); while for certain situations during summer 2012 the atmospheric absorptance varied in the range of 24-36\%. A substantial increment in $\mathrm{ABS}_{\mathrm{ATM}}$ on 27 July was a consequence of a considerable (almost an order of magnitude) increase in AOD, accompanied by growth in the average order of scattering.

The direct radiative effect of aerosol for fixed characteristics of underlying surface and fixed solar zenith angle primarily depends on AOD, single scattering albedo, and the asymmetry factor (Zhou et al., 2005; Yu et al., 2006; Tomasi et al., 2015). The results, presented in Fig. 13b, show a cooling effect of aerosol at the top and bottom of the atmosphere. As expected, the interrelation between DRE values was determined by aerosol optical depth and was maximal (in absolute value) on 27 July 2012: $\Phi_{\mathrm{BOA}}=-150 \mathrm{~W} \mathrm{~m}^{-2}$, $\Phi_{\mathrm{TOA}}=-75 \mathrm{~W} \mathrm{~m}^{-2}, \Phi_{\mathrm{ATM}}=75 \mathrm{~W} \mathrm{~m}^{-2}$. Under the background conditions, the DRE value was minimal: $-13 \mathrm{~W} \mathrm{~m}^{-2}$ at $\mathrm{BOA}$ and $-5 \mathrm{~W} \mathrm{~m}^{-2}$ at TOA.

The AOD influence on direct radiative effect efficiency $\Phi^{\mathrm{e}}$ compared to DRE is much less pronounced, making it possible to estimate the influence of absorbing and scattering aerosol properties on radiative effects. However, it should be kept in mind that the increase of multiple scattering effects and attenuation of the transmitted radiation for large AOD moderate their effect (Conant et al., 2003).

For small atmospheric turbidity, the aerosol single scattering albedo weakly influences the radiative effect efficiency, and high $\left|\Phi^{\mathrm{e}}\right|$ values at TOA, BOA, and in the atmosphere are primarily determined by AOD (Case 1, Fig. 13c). The increase of efficiency for the lowest AOD range was also noted by other authors (see e.g. García et al., 2012; background continental regions).

The aerosol optical depths in the ordinary smoke and on 14 July are close in value, whereas SSA values substan- 

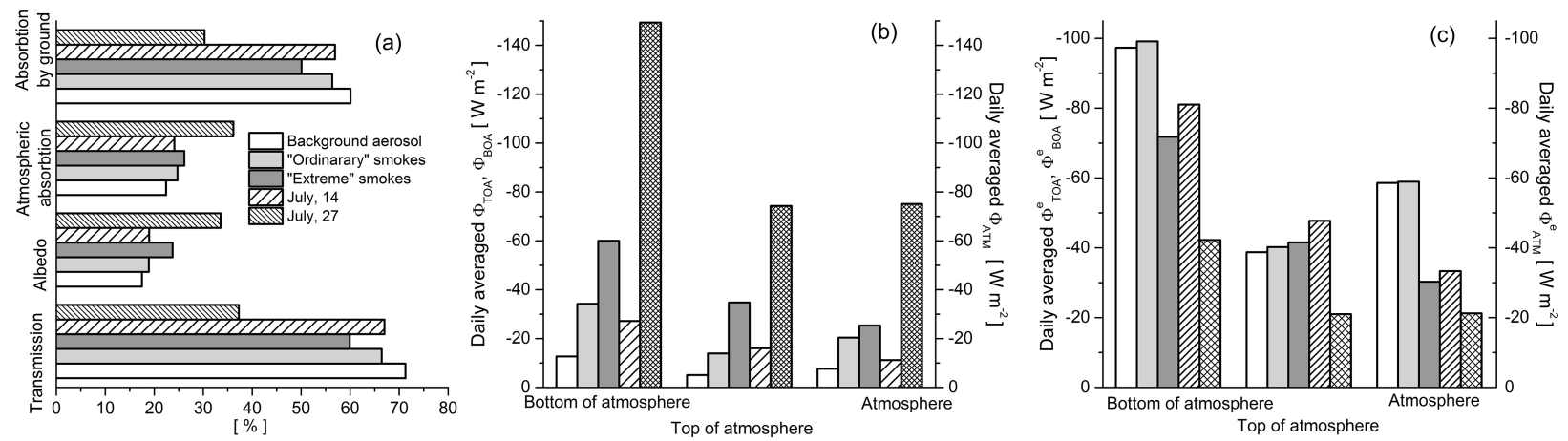

Figure 13. Radiative effects of aerosol under different atmospheric conditions.

tially differ (Table 5). A consequence of this is the inequality $\mid \Phi^{\mathrm{e}}$ (Case 2$)|>| \Phi^{\mathrm{e}}$ (Case 4$) \mid$, primarily because of the higher absorptance of aerosol particles in ordinary smoke. The comparison of cases 3-5 (extreme smoke) shows that the $\mid \Phi^{\mathrm{e}}($ Case 4$) \mid$ value is maximal for SSA close to unity (Fig. 13c), suggesting that the influence of absorbing and scattering aerosol properties on radiative effect efficiency is moderated for high AOD values.

\section{Conclusion}

Previous studies showed that smoke from vegetation burning, together with large volcanic eruptions, are the most intense natural sources of aerosol-gas emissions in the boreal zones of the planet. They strongly influence the radiation budget on large scales over a few weeks. One such event, i.e. extreme smoke due to massive forest fires, took place during summer 2012 in a few Siberian regions.

In this work, we present the results of a complex study of the optical and microphysical characteristics and radiation effects of aerosol, observed under the conditions of severe smoke turbidity of the atmosphere. The basis for analysis was photometric observations (AERONET/Tomsk-22) of spectral solar radiation with the use of the algorithms of solution of inverse problems of atmospheric optics and model calculations of the main components of the shortwave radiation budget. The obtained radiation characteristics from the 2012 extreme fire event are compared with data from multiyear (2003-2013) observations under the background conditions for ordinary smoke, as well as with the results obtained by other authors.

Intensive wildfires in 2012 in Siberia led to high aerosol loading of the atmosphere: the average $\operatorname{AOD}(500 \mathrm{~nm})$ in the period of extreme smoke was $0.95 \pm 0.86$, a factor of 6 larger than under the background conditions $(0.16 \pm 0.08)$, and almost a factor of 2.5 larger than AOD in ordinary smoke $(0.36 \pm 0.18)$. The AOD value exceeded 3 in certain periods of measurements (on 24-28 July).
Like at other AERONET sites, where smoke aerosol was recorded, in Tomsk the volume aerosol size distributions were bimodal with a dominating fine-mode fraction. In JuneAugust 2012, the mean median radius of fine fraction $r_{\mathrm{v}}^{\mathrm{f}}$ had increased to $0.18 \mu \mathrm{m}$ compared to ordinary smoke $\left(r_{\mathrm{v}}^{\mathrm{f}}=\right.$ $0.16 \mu \mathrm{m})$. The width of the fine-mode distribution increased, as was the case in the period of intense fires during summer 2004-2005 in Alaska (Eck et al., 2009). In contrast to data from multi-year observations, in summer 2012 an increase in the volume concentration and median radius of the coarse mode was observed with growing AOD.

The average imaginary refractive index of the 2012 Tomsk fires shows low values and a relatively large decrease in $\kappa_{\lambda}$ as the wavelength grows from $440 \mathrm{~nm}(0.0067)$ to $675 \mathrm{~nm}$ (0.0054). The $\kappa_{\lambda}$ variations in the wavelength interval of $675-1020 \mathrm{~nm}$ are not so large. At the same time, in ordinary smoke the imaginary part of the refractive index showed spectral behaviour close to neutral $\left(\kappa_{\lambda} \approx 0.01\right)$.

A consequence of small values of the imaginary index of refraction coupled with the large fine-mode particle radius was, on average, quite high single scattering albedos of smoke aerosol, weakly varying with wavelength (0.96). A similar situation was also observed at other AERONET sites, located in the boreal zone of Eurasia during extended wildfires, e.g. in Moscow (2002 and 2010), Alaska (2004 and 2005). At the same time, increasing spectral behaviour of single scattering albedo with growing wavelength was observed in certain periods of smoke turbidities. Possibly, this spectral dependence was because brown carbon, which absorbs most intensely in ultraviolet spectral region, was present in the atmosphere. A comparative analysis also showed that SSA values and their spectral dependence differ between extreme and ordinary smoke. In the latter case, the increase in absorptance of aerosol particles and decrease in SSA with growing wavelength correspond well to the character of SSA variations, recorded in the boreal zone of USA and Canada according to data from multi-year observations (Dubovik et al., 2002).

Extraordinary events such as severe fires (Siberia, 2012; Moscow, 2010; etc.) are quite rare in occurrence. However, when optical and microphysical characteristics obtained dur- 
ing these periods of time are included in the total data set (ordinary smoke, usual conditions), they may introduce substantial changes in the statistical characteristics of aerosol, typical for a given region (see e.g. Sayer et al., 2014), and will lead to a greater uncertainty in estimates of radiationclimatic effects of aerosol. In our opinion, it is more correct to use the obtained information for analysing characteristics of "pure" smoke aerosol (in view of its predominating contribution), as well as for estimating maximal radiation effect of smoke.

The results of simulating the diurnally average radiative characteristics, presented in the work, reflect the average radiative effects of smoke and background aerosol. Compared to background conditions and ordinary smoke, under the conditions of 2012 extreme fires the cooling effect of aerosol intensifies (predominately due to a substantial increase in AOD): the direct radiative effects at the bottom and top of the atmosphere are $-13,-35$, and $-60 \mathrm{~W} \mathrm{~m}^{-2}$, and $-5,-14$, and $-35 \mathrm{~W} \mathrm{~m}^{-2}$ respectively. Values of direct radiative effect efficiency $\Phi^{\mathrm{e}}$ under the background conditions and under the conditions of ordinary smoke are comparable $\left(\Phi_{\mathrm{BOA}}^{\mathrm{e}} \sim-100 \mathrm{~W} \mathrm{~m}^{-2}\right.$, $\left.\Phi_{\mathrm{TOA}}^{\mathrm{e}} \sim-40 \mathrm{~W} \mathrm{~m}^{-2}, \Phi_{\mathrm{ATM}}^{\mathrm{e}} \sim-60 \mathrm{~W} \mathrm{~m}^{-2}\right)$. During the fire event in summer 2012 direct radiative effect efficiency varies in range: at the $\mathrm{BOA}$ it is $-80,-40 \mathrm{~W} \mathrm{~m}^{-2}$, at the TOA it is $-50,-20 \mathrm{~W} \mathrm{~m}^{-2}$ and in the atmosphere it is -35 , $-20 \mathrm{~W} \mathrm{~m}^{-2}$. These results show that the influence of absorbing and scattering aerosol properties on radiative effect efficiency is moderated for high AOD values. We note that this work presents estimates of daytime values of aerosol radiation effects under different atmospheric conditions. The issue of the uncertainty of these estimates, caused by insufficiently exact information on the input parameters of radiation calculations, requires further study.

\section{Data availability}

The text provides links to data sources, which we used: http:/giovanni.sci.gsfc.nasa.gov/giovanni/ (NASA GES DISC, 2016), http://aeronet.gsfc.nasa.gov (GSFC NASA, 2015), http://lance-modis.eosdis.nasa.gov/cgi-bin/imagery/ firemaps.cgi (GSFC Terrestrial Information Systems Laboratory, 2016), http://rp5.ru (Raspisaniye Pogodi Ltd., 2016), and http://rtweb.aer.com/continuum_frame.html (Atmospheric and Environmental Research, 2016).

Acknowledgements. The authors would like to thank Thomas F. Eck at NASA Goddard Space Flight Center for fruitful discussions of certain issues.

Edited by: A. Kokhanovsky

Reviewed by: three anonymous referees

\section{References}

Anderson, G., Clough, S., Kneizys, F., Chetwynd, J., and Shettle, E.: AFGL Atmospheric Constituent Profiles (0-120 km), Air Force Geophysics Laboratory, AFGL-TR-86-0110, Environmental Research Paper, N 954, Hanscom AFB, MA 01731, USA, 1986.

Andreae, M. O. and Gelencsér, A.: Black carbon or brown carbon? The nature of light-absorbing carbonaceous aerosols, Atmos. Chem. Phys., 6, 3131-3148, doi:10.5194/acp-6-3131-2006, 2006.

Arshinov, M. Yu., Belan, B. D., Davydov, D. K., Inouye, G., Maksyutov, Sh., Machida, T., and Fofonov, A. V.: Vertical distribution of greenhouse gases above Western Siberia by the longterm measurement data, Atmos. Ocean. Opt., 22, 316-324, 2009.

Atmospheric and Environmental Research: MT_CKD Continuum Model, Lexington, USA, available at: http://rtweb.aer.com/ continuum_frame.html, last access: 2016.

Bedareva, T. V. and Zhuravleva, T. B.: Retrieval of aerosol scattering phase function and single scattering albedo according to data of radiation measurements in solar almucantar: numerical simulation, Atmos. Ocean. Opt., 24, 373-384, 2011.

Bedareva, T. V., Sviridenkov, M. A., and Zhuravleva, T. B.: Retrieval of aerosol optical and microphysical characteristics according to data of ground-based spectral measurements of direct and scattered solar radiation. Part 1. Testing of Algorithm, Atmos. Ocean. Opt., 26, 24-34, $2013 \mathrm{a}$.

Bedareva, T. V., Sviridenkov, M. A., and Zhuravleva, T. B.: Retrieval of aerosol optical and microphysical characteristics according to data of ground-based spectral measurements of direct and scattered solar radiation. Part 2. Approbation of Algorithm, Atmos. Ocean. Opt., 26, 107-117, 2013b.

Bedareva, T. V., Sviridenkov, M. A., and Zhuravleva, T. B.: Retrieval of dust aerosol optical and microphysical properties from ground-based Sun-sky radiometer measurements in approximation of randomly oriented spheroids, J. Quant. Spectrosc. Ra., 146, 140-157, doi:10.1016/j.jqsrt.2014.05.006, 2014.

Bergstrom, R. W., Russell, P. B., and Hignett, P.: Wavelength dependence of the absorption of black carbon particles: Predictions and results from the TARFOX experiment and implications for the aerosol single scattering albedo, J. Atmos. Sci., 59, 567-577, 2002.

Bergstrom, R. W., Pilewskie, P., Russell, P. B., Redemann, J., Bond, T. C., Quinn, P. K., and Sierau, B.: Spectral absorption properties of atmospheric aerosols, Atmos. Chem. Phys., 7, 5937-5943, doi:10.5194/acp-7-5937-2007, 2007.

Bond, T. C.: Spectral dependence of visible light absorption by carbonaceous particles emitted from coal combustion, Geophys. Res. Lett., 28, 4075-4078, 2001.

Bond, T. C. and Bergstrom, R. W.: Light Absorption by Carbonaceous Particles: An Investigative Review, Aerosol Sci. Tech., 40, 27-67, doi:10.1080/02786820500421521, 2006.

Chakrabarty, R. K., Gyawali, M., Yatavelli, R. L. N., Pandey, A., Watts, A. C., Knue, J., Chen, L.-W. A., Pattison, R. R., Tsibart, A., Samburova, V., and Moosmüller, H.: Brown carbon aerosols from burning of boreal peatlands: microphysical properties, emission factors, and implications for direct radiative forcing, Atmos. Chem. Phys., 16, 3033-3040, doi:10.5194/acp-163033-2016, 2016. 
Chen, Y. and Bond, T. C.: Light absorption by organic carbon from wood combustion, Atmos. Chem. Phys., 10, 1773-1787, doi:10.5194/acp-10-1773-2010, 2010.

Chubarova, N., Smirnov, A., and Holben, B. N.: Aerosol properties in Moscow according to 10 years of AERONET measurements at the meteorological observatory of Moscow state university, Geography, Environment, Sustainability, 4, 19-32, 2011.

Chubarova, N., Nezval', Ye., Sviridenkov, I., Smirnov, A., and Slutsker, I.: Smoke aerosol and its radiative effects during extreme fire event over Central Russia in summer 2010, Atmos. Meas. Tech., 5, 557-568, doi:10.5194/amt-5-557-2012, 2012.

Conant, W. C., Seinfeld, J. H., Wang, J., Carmichael, G. R., Tang, Y., Uno, I., Flatau, P. J., Markowicz, K. M., and Quinn, P. K.: A model for the radiative forcing during ACE-Asia derived from CIRPAS Twin Otter and R/V Ronald H. Brown data and comparison with observations, J. Geophys. Res., 108, 8661, doi:10.1029/2002JD003260, 2003.

Dubovik, O., Smirnov, A., Holben, B., King, M., Kaufman, Y., Eck, T., and Slutsker, I.: Accuracy assessments of aerosol optical properties retrieved from Aerosol Robostic Network (AERONET) Sun and sky radiance measurements, J. Geophys. Res., 105, 9791-9806, 2000.

Dubovik, O., Holben, B., Eck, T., Smirnov, A., Kaufman, Y., King, M., Tanré, D., and Slutsker I.: Variability of absorption and optical properties of key aerosol types observed in worldwide locations, J. Atmos. Sci., 59, 590-608, 2002.

Dubovik, O. T. and King, M.: A flexible inversion algorithm for retrieval aerosol optical properties from Sun and sky radiance measurements, J. Geophys. Res., 105, 20673-20696, 2000.

Eck, T. F., Holben, B. N., Reid, J. S., Sinyuk, A., Hyer, E. J., O'Neill, N. T., Shaw, G. E., Vande Castle, J. R., Chapin, F. S., Dubovik, O., Smirnov, A., Vermote, E., Schafer, J. S., Giles, D., Slutsker, I., Sorokine, M., and Newcomb, W. W.: Optical properties of boreal region biomass burning aerosols in central Alaska and seasonal variation of aerosol optical depth at an Arctic coastal site, J. Geophys. Res., 114, D11201, doi:10.1029/2008JD010870, 2009.

Esteve, A. R., Highwood, E. J., and Ryder, C. L.: A case study of the radiative effect of aerosols over Europe: EUCAARI-LONGREX, Atmos. Chem. Phys., 16, 7639-7651, doi:10.5194/acp-16-76392016, 2016.

Fontenla, J., White, O. R., Fox, P. A., Avert, E. H., and Kurucz, R. L.: Calculation of solar irradiances, I. Synthesis of the solar spectrum, Astrophys. J., 518, 480-500, 1999.

García, O. E., Díaz, A. M., Exposito, F. J., Díaz, J. P., Dubovik, O., Dubuisson, P., Roger, J.-C., Eck, T. F., Sinyuk, A., Derimian, Y., Dutton, E. G., Schafer, J. S., Holben, B. N., and García, C. A.: Validation of AERONET estimates of atmospheric solar fluxes and aerosol radiative forcing by groundbased broadband measurements, J. Geophys. Res., 113, D21207, doi:10.1029/2008JD010211, 2008.

García, O. E., Díaz, J. P., Expósito, F. J., Díaz, A. M., Dubovik, O., Derimian, Y., Dubuisson, P., and Roger, J.-C.: Shortwave radiative forcing and efficiency of key aerosol types using AERONET data, Atmos. Chem. Phys., 12, 5129-5145, doi:10.5194/acp-125129-2012, 2012.

Garcia, R. D., Garcia, O. E., Cuevas, E., Cachorro, V. E., RomeroCampos, P. M., Ramos, R., and de Frutos, A. M.: Solar radiation measurements compared to simulations at the BSRN Izana sta- tion: Mineral dust radiative forcing and efficiency study, J. Geophys. Res., 119, 179-194, doi:10.1002/2013JD020301, 2014.

Giles, D. M., Holben, B. N., Eck, T. F., Sinyuk, A., Smirnov, A., Slutsker, I., Dickerson, R. R., Thompson, A. M., and Schafer, J. S.: An analysis of AERONET aerosol absorption properties and classifications representative of aerosol source regions, J. Geophys. Res., 117, D17203, doi:10.1029/2012JD018127, 2012.

Gorchakov, G. I., Sitnov, S. A., Sviridenkov, M. A., Semoutnikova, E. G., Emilenko, A. S., Isakov, A. A., Kopeikin, V. M., Karpov, A. V., Gorchakova, I. A., Verichev, K. S., Kurbatov, G. A., and Ponomareva, T. Ya.: Satellite and ground-based monitoring of smoke in the atmosphere during the summer wildfires in European Russia in 2010 and Siberia in 2012, Int. J. Remote Sens., 35, 5698-5721, 2014.

Groisman, P. Ya., Sherstyukov, B. G., Razuvaev, V. N., Knight, R. W., Enloe, J. G., Stroumentova, N. S., Whitfield, P. H., Førland, E., Hannsen-Bauer, I., Tuomenvirt, H., Aleksandersson, H., Mescherskaya, A., and Karl, T. R.: Potential forest fire danger over Northern Eurasia: Changes during the 20th century, Global Planet. Change, 56, 371-386, 2007.

GSFC NASA: AERONET Data Download Tool, USA, available at: http://aeronet.gsfc.nasa.gov, last access: January 2015.

GSFC Terrestrial Information Systems Laboratory: LANCEMODIS data system, NASA, USA, available at: http:// lance-modis.eosdis.nasa.gov/cgi-bin/imagery/firemaps.cgi, last access: March 2016.

Hammer, M. S., Martin, R. V., van Donkelaar, A., Buchard, V., Torres, O., Ridley, D. A., and Spurr, R. J. D.: Interpreting the ultraviolet aerosol index observed with the OMI satellite instrument to understand absorption by organic aerosols: implications for atmospheric oxidation and direct radiative effects, Atmos. Chem. Phys., 16, 2507-2523, doi:10.5194/acp-16-2507-2016, 2016.

Hess, M., Koepke, P., and Schult, I.: Optical properties of aerosols and clouds: The software package OPAC, B. Am. Meteorol. Soc., 79, 831-844, 1998.

Holben, B. N., Eck, T. F., Slutsker, I., Tanre, D., Buis, J. P., Setzer, A., Vermote, E., Reagan, J. A., Kaufman, Y. J., Nakadjima, T., Lavenu, F., Jankowiak, I., and Smirnov, A.: AERONET - A federated instrument network and data archive for aerosol characterization, Remote Sens. Environ., 66, 1-16, 1998.

Holben, B. N., Eck, T. F., Slutsker, I., Smirnov, A., Sinyuk, A., Schafer, J., Giles, D., and Dubovik, O.: AERONET's Version 2.0 quality assurance criteria, Remote Sensing of Atmosphere and Clouds, Proc. SPIE, 6408, 64080Q, doi:10.1117/12.706524, 2006.

Jethva, H. and Torres, O.: Satellite-based evidence of wavelengthdependent aerosol absorption in biomass burning smoke inferred from Ozone Monitoring Instrument, Atmos. Chem. Phys., 11, 10541-10551, doi:10.5194/acp-11-10541-2011, 2011.

Kabanov, D. M. and Sakerin, S. M.: Variations of the characteristics of the aerosol optical depth under conditions of forest fires, Proc. of SPIE: Thirteenth Joint International Symposium on Atmospheric and Ocean Optics. Atmospheric Physics, 2-7 July 2006, Tomsk, Russia, 6522, 65221J-1-65221J-6, 2006.

Kirchstetter, T. W., Novakov, T., and Hobbs, P. V.: Evidence that the spectral dependence of light absorption by aerosols is affected by organic carbon, J. Geophys. Res., 109, D21208, doi:10.1029/2004jd004999, 2004. 
Komarov, V. S. and Lomakina, N. Ya.: Statistical models of the atmospheric boundary layer, IAO Publishing House, Tomsk, Russia, 2008 (in Russian).

Kozlov, V. S., Yausheva, E. P., Terpugova, S. A., Panchenko, M. V., Chernov, D. G., and Shmargunov V. P.: Optical-microphysical properties of smoke haze from Siberian forest fires in summer 2012, Int. J. Remote Sens., 35, 5722-5741, 2014.

Levy, R. C., Mattoo, S., Munchak, L. A., Remer, L. A., Sayer, A. M., Patadia, F., and Hsu, N. C.: The Collection 6 MODIS aerosol products over land and ocean, Atmos. Meas. Tech., 6, 29893034, doi:10.5194/amt-6-2989-2013, 2013.

Lewis, K., Arnott, W. P., Moosmuller, H., and Wold, C. E.: Strong spectral variation of biomass smoke light absorption and single scattering albedo observed with a novel dualwavelength photoacoustic instrument, J. Geophys. Res., 113, D16203 doi:10.1029/2007jd009699, 2008.

Lu, Z., Streets, D. J., Winijkul, E., Yan, F., Chen, Y., Bond, T. C., Feng, Y., Dubey, M. K., Liu, S., Pinto, J. P., and Carmichael, G. R.: Light Absorption Properties and Radiative Effects of Primary Organic Aerosol Emissions, Environ. Sci. Technol., 49, 48684877, doi:10.1021/acs.est.5b00211, 2015.

Moody, E. G., King, M. D., Platnick, S., Schaaf, C. B., and Gao, F.: Spatially compete global spectral surface albedos: value-added datasets derived from Terra MODIS Land products, IEEE T. Geosci. Remote, 43, 144-158, 2005.

Moosmüller, H, Chakrabarty, R. K., and Arnott, W. P.: Aerosol light absorption and its measurement: A review, J. Quant. Spectrosc. Ra., 110, 844-878, 2009.

Myhre, G., Berntsen, T. K., Haywood, J. M., Sundet, J. K., Holben, B. N., Johnsrud, M., and Stordal, F.: Modeling the solar radiative impact of aerosols from biomass burning during the Southern African Regional Science Initiative (SAFARI-2000) experiment, J. Geophys. Res., 108, 8501, doi:10.1029/2002JD002313, 2003.

NASA GES DISC: Giovanni online data system, USA, available at: http://giovanni.sci.gsfc.nasa.gov/giovanni/, last access: April 2016.

Nikonovas, T., North, P. R. J., and Doerr, S. H.: Smoke aerosol properties and ageing effects for northern temperate and boreal regions derived from AERONET source and age attribution, Atmos. Chem. Phys., 15, 7929-7943, doi:10.5194/acp-15-79292015, 2015.

O’Neill, N. T., Eck, T. F., Holben, B. N., Smirnov, A., Dubovik, O., and Royer, A.: Bimodal size distribution influences on the variation of Angstrom derivatives in spectral and optical depth space, J. Geophys. Res., 106, 9787-9806, doi:10.1029/2000JD900245, 2001.

O’Neill, N. T., Eck, T. F., Smirnov, A., Holben, B. N., and Thulasiraman, S.: Spectral discrimination of coarse and fine mode optical depth, J. Geophys. Res., 108, 4559, doi:10.1029/2002JD002975, 2003.

Panchenko, M. V., Zhuravleva, T. B., Terpugova, S. A., Polkin, V. V., and Kozlov, V. S.: An empirical model of optical and radiative characteristics of the tropospheric aerosol over West Siberia in summer, Atmos. Meas. Tech., 5, 1513-1527, doi:10.5194/amt5-1513-2012, 2012.

Panchenko, M. V., Zhuravleva, T. B., Kozlov, V. S., Nasrtdinov, I. M., Pol'kin, V. V., Terpugova, S. A., and Chernov, D. G.: Estimation of Aerosol Radiation Effects under Background and Smoke- haze Atmospheric Conditions over Siberia from Empirical Data, Russ. Meteorol. Hydrol., 41, 104-111, 2016.

Polyakov, D. V., Barashkova, N. K., and Kuzhevskaya, I. V.: Weather and Climate Description of Anomalous Summer 2012 in Tomsk Region, Russ. Meteorol. Hydrol., 39, 22-28, 2014.

Raspisaniye Pogodi Ltd.: Reliable prognosis, St. Petersburg, Russia, available at: http://rp5.ru, last access: April 2016.

Reid, J. S., Hobbs, P. V., Ferek, R. J., Blake, D. R., Martins, J. V., Dunlap, M. R., and Liousse, C.: Physical, chemical, and optical properties of regional hazes dominated by smoke in Brazil, J. Geophys. Res., 103, 32059-32080, 1998.

Reid, J. S., Koppmann, R., Eck, T. F., and Eleuterio, D. P.: A review of biomass burning emissions part II: intensive physical properties of biomass burning particles, Atmos. Chem. Phys., 5, 799825, doi:10.5194/acp-5-799-2005, 2005a.

Reid, J. S., Eck, T. F., Christopher, S. A., Koppmann, R., Dubovik, O., Eleuterio, D. P., Holben, B. N., Reid, E. A., and Zhang, J.: A review of biomass burning emissions part III: intensive optical properties of biomass burning particles, Atmos. Chem. Phys., 5, 827-849, doi:10.5194/acp-5-827-2005, 2005b.

Russell, P. B., Bergstrom, R. W., Shinozuka, Y., Clarke, A. D., DeCarlo, P. F., Jimenez, J. L., Livingston, J. M., Redemann, J., Dubovik, O., and Strawa, A.: Absorption Angstrom Exponent in AERONET and related data as an indicator of aerosol composition, Atmos. Chem. Phys., 10, 1155-1169, doi:10.5194/acp-101155-2010, 2010.

Sakerin, S. M. (Ed.): Study of radiative characteristics of aerosol in Asian part of Russia, Publishing House of Institute of Atmospheric Optics SB RAS, Tomsk, Russia, 484 pp., 2012 (in Russian).

Sakerin, S. M. and Kabanov, D. M.: Spectral dependence of the atmosphere aerosol optical depth near 0.37-4 $\mu \mathrm{m}$, Atmos. Ocean. Opt., 20, 141-149, 2007.

Sakerin, S. M. and Kabanov, D. M.: Finely and coarsely dispersed components of atmospheric aerosol optical depth in the region of Tomsk: interannual and seasonal variations, Proc. of SPIE, 1316, 9680, doi:10.1117/12.22050, 2015.

Sakerin, S. M., Beresnev, S. A., Gorda, S. Yu., Kabanov, D. M., Kornienko, G. I., Markelov, Yu. I., Mikhalev, A. V., Nikolashkin, S. V., Panchenko, M. V., Poddubnyi, V. A., Pol'kin, V. V., Smirnov, A., Tashchilin, M. A., Turchinovich, S. A., Turchinovich, Yu. S., Holben, B., and Eremina, T. A.: Characteristics of the annual behavior of the spectral aerosol optical depth of the atmosphere under conditions of Siberia, Atmos. Ocean. Opt., 22, 446-456, 2009.

Sakerin, S. M., Kabanov, D. M., Nasrtdinov, I. M., Turchinovich, S. A., and Turchinovich, Yu. S.: The results of two-point experiments on the estimation of the urban anthropogenic effect on the characteristics of atmospheric transparency, Atmos. Ocean. Opt., 23, 88-94, 2010.

Sakerin, S. M., Andreev, S. Yu., Kabanov, D. M., Nikolashkin, S. V., Prakhov, A. N., Radionov, V. F., Turchinovich, Yu. S., Chernov, D. G., Holben, B. N., and Smirnov, A.: On results of studies of atmospheric aerosol optical depth in arctic regions, Atmos. Ocean. Opt., 27, 517-528, 2014.

Sayer, A. M., Hsu, N. C., Eck, T. F., Smirnov, A., and Holben, B. N.: AERONET-based models of smoke-dominated aerosol near source regions and transported over oceans, and implications for 
satellite retrievals of aerosol optical depth, Atmos. Chem. Phys., 14, 11493-11523, doi:10.5194/acp-14-11493-2014, 2014.

Schuster, G. L., Dubovik, O., and Arola, A.: Remote sensing of soot carbon - Part 1: Distinguishing different absorbing aerosol species, Atmos. Chem. Phys., 16, 1565-1585, doi:10.5194/acp16-1565-2016, 2016.

Shakina, N. P. and Ivanova, A. R.: The Blocking Anticyclones: the State of Studies and Forecasting, Russ. Meteorol. Hydrol., 35, 721-730, 2010.

Sklyadneva, T. K., Ivlev, G. A., Belan, B. D., Arshinov, M. Yu., and Simonenkov, D. V.: The radiation regime of Tomsk in conditions of a smoky haze, Atmos. Ocean. Opt., 28, 215-222, 2015 (in Russian).

Smirnov, A., Holben, B. N., Eck, T. F., Dubovik, O., and Slutsker, I.: Cloud screening and quality control algorithms for the AERONET data base, Remote Sens. Environ., 73, 337-349, 2000.

Tomasi, C., Lanconelli, C., Lupi, A., and Mazzola, M.: Diurnally averaged direct aerosol-induced radiative forcing from cloud-free sky field measurements performed during seven regional experiments, in: Light Scattering Reviews 9, edited by: Kokhanovsky, A., Springer Praxis Books, Chichester, UK, 297425, 2015.

Torres, O., Bhartia, P. K., Herman, J. R., Ahmad, Z., and Gleason, J.: Derivation of aerosol propertiesfrom satellite measurements of backscattered ultraviolet radiation: theoretical basis, J. Geophys. Res., 103, 17099-17110, doi:10.1029/98JD00900, 1998.

Tvorogov, S. D., Zhuravleva, T. B., Rodimova, O. B., and Firsov, K. M.: Theory of series of exponents and its application for analysis of radiation processes, in: Problems of Global Climatology and Ecodynamics. Anthropogenic Effects on the State of Planet Earth, edited by: Cracknell, A. P., Krapivin, V. F., and Varotsos, C. A., Springer/Praxis, Chichester, UK, 211-240, 2008.

Vinogradova, A. A., Smirnov, N. S., Korotkov, V. N., and Romanovskaya, A. A.: Forest Fires in Siberia and the Far East: Emissions and Atmospheric Transport of Black Carbon to the Arctic, Atmos. Ocean. Opt., 28, 566-574, 2015.
Yu, H., Kaufman, Y. J., Chin, M., Feingold, G., Remer, L. A., Anderson, T. L., Balkanski, Y., Bellouin, N., Boucher, O., Christopher, S., DeCola, P., Kahn, R., Koch, D., Loeb, N., Reddy, M. S., Schulz, M., Takemura, T., and Zhou, M.: A review of measurement-based assessments of the aerosol direct radiative effect and forcing, Atmos. Chem. Phys., 6, 613-666, doi:10.5194/acp-6-613-2006, 2006.

Zhong, M. and Jang, M.: Dynamic light absorption of biomassburning organic carbon photochemically aged under natural sunlight, Atmos. Chem. Phys., 14, 1517-1525, doi:10.5194/acp-141517-2014, 2014.

Zhou, M., Yu, H., Dickinson, R., Dubovik, O., and Holben, B.: A normalized description of the direct effect of key aerosol types on solar radiation as estimated from AERONET aerosols and MODIS albedo, J. Geophys. Res., 110, D19202, doi:10.1029/2005JD005909, 2005.

Zhuravleva, T. B. and Sakerin, S. M..: Simulation of direct aerosol radiative forcing for typical summer conditions of Siberia. Part II: Variability range and sensitivity to the input parameters, Atmos. Ocean. Opt, 22, 74-83, 2009.

Zhuravleva, T. B., Kabanov, D. M., Sakerin, S. M., and Firsov, K. M.: Simulation of direct aerosol radiative forcing for typical summer conditions of Siberia. Part 1: Method of calculation and choice of the input parameters, Atmos. Ocean. Opt., 22, 63-73, 2009.

Zhuravleva, T. B., Sakerin, S. M., Bedareva, T. V., Kabanov, D. M., Nasrtdinov, I. M., and Chesnokova, T. Yu.: Solar radiative fluxes in the clear-sky atmosphere of Western Siberia: A comparison of simulations with field measurements, Atmos. Ocean. Opt., 27, 176-186, 2014. 